\title{
Discoidin domain receptor 1 modulates insulin receptor signaling and biological responses in breast cancer cells
}

\author{
Veronica Vella ${ }^{1, *}$, Roberta Malaguarnera ${ }^{2,}{ }^{*}$, Maria Luisa Nicolosi ${ }^{2}$, Chiara Palladino ${ }^{2}$, \\ Cristina Spoleti ${ }^{2}$, Michele Massimino ${ }^{3}$, Paolo Vigneri ${ }^{3}$, Michele Purrello ${ }^{4}$, Marco \\ Ragusa $^{4}$, Andrea Morrione ${ }^{5}$ and Antonino Belfiore ${ }^{2}$ \\ ${ }^{1}$ School of Motor Sciences, Faculty of Human and Social Sciences, Kore University of Enna, Enna, Italy \\ ${ }^{2}$ Endocrinology, Department of Health Sciences, University Magna Graecia of Catanzaro, Catanzaro, Italy \\ ${ }^{3}$ Department of Clinical and Experimental Medicine, Faculty of Medicine, University of Catania, Catania, Italy \\ ${ }^{4}$ Department of Biomedical and Biotechnological Sciences, Unit of BioMolecular, Genome, and Complex System BioMedicine, \\ University of Catania, Catania, Italy \\ ${ }^{5}$ Department of Urology and Biology of Prostate Cancer Program, Sidney Kimmel Cancer Center, Thomas Jefferson University, \\ Philadelphia, PA, USA \\ *These authors have contributed equally to this work \\ Correspondence to: Antonino Belfiore, email: belfiore@unicz.it \\ Keywords: insulin receptor, insulin receptor isoforms, DDR 1, breast cancer \\ Received: February 23, $2017 \quad$ Accepted: April 14, $2017 \quad$ Published: May 19, 2017 \\ Copyright: Vella et al. This is an open-access article distributed under the terms of the Creative Commons Attribution License 3.0 (CC \\ BY 3.0), which permits unrestricted use, distribution, and reproduction in any medium, provided the original author and source are \\ credited.
}

\section{ABSTRACT}

The fetal isoform A of the insulin receptor (IR-A) is frequently overexpressed in a variety of malignancies including breast cancer. IR overexpression has a recognized role in cancer progression and resistance to anticancer therapies. In particular, IR-A has a peculiar mitogenic potential and is activated not only by insulin but also by IGF-2. Previously, we identified discoidin domain receptor 1 (DDR1) as a new IR-A interacting protein. DDR1, a non-integrin collagen tyrosine kinase receptor, is overexpressed in several malignancies and plays a role in cancer progression and metastasis.

We now evaluated whether DDR1 is able to exert a role in breast cancer biology by functionally cross-talking with IR. In MCF-7 human breast cancer cells, IR and DDR1 co-immunoprecipitated and co-localized after insulin or IGF-2 stimulation. In a panel of breast cancer cells, DDR1 knockdown by specific siRNAs markedly inhibited IR downstream signaling as well as proliferation, migration and colony formation in response to insulin and IGF-2. These effects were accompanied by reduction of IR protein and mRNA expression, which involved both transcriptional and post-transcriptional effects. DDR1 overexpression elicited opposite effects. Bioinformatics analysis of public domain databases showed that IR and DDR1 coexpression significantly correlates with several clinically relevant histopathological and molecular features of human breast carcinomas.

These findings demonstrate that, in human breast cancer cells, DDR1 regulates IR expression and ligand dependent biological actions. This novel functional crosstalk is likely clinically relevant and may become a new molecular target in breast cancer.

\section{INTRODUCTION}

Dysregulation of the insulin/IGF signaling (IIGFs), involving the overexpression of receptors for IGF-1 and/ or insulin (IGF-1R and IR) and/or cognate ligands (IGF-
1, IGF-2), has an important role in the early phases of carcinogenesis of breast cancer, and is associated with cancer progression and metastases and resistance to a variety of therapies [1-4]. IIGFs is especially relevant to Epithelial Mesenchymal Transition (EMT) [5] and 
other stem-like features [6], which play a key role in cancer development and recurrence. However, IGF-1R inhibitors have shown limited benefit in cancer when used as single therapy [7-10]. Thus, to exploit the anticancer potential of IIGFs inhibition, there is an urgent need to better understand IIGFs activities and interactions. A deep understanding of the molecular mechanisms for this failure will open the way to successful therapies able to eradicate breast cancer. A major mechanism of resistance to anti-IGF-1R drugs involves the IR, which is commonly overexpressed in breast cancer and predominantly expressed as the so called 'fetal isoform' (IR-A), which is a bona fide receptor for IGF-2 and proinsulin $[11,12]$. Significantly, the IR-A/IGF-2 autocrine loop plays a key role in many cancer histotypes, including breast cancer $[13,14]$.

Notably, IRs and IGF-1R signaling and actions may undergo diversification following crosstalk with other membrane receptors. In a previous study, aimed at discovering new substrates/mediators of the IGF-2/IR-A pathway, we reported that DDR1 is found in multiprotein complexes associated with tyrosine-phosphorylated IR in response to IGF-2 and to a lesser extent to insulin [15]. DDR1 belongs to the discoidin domain receptors (DDRs), family, which includes two members, DDR1 and DDR2 recognized as collagen receptors $[16,17]$. Upon binding to collagens, DDR1 undergoes slow but prolonged phosphorylation at several tyrosine residues, which potentially serve as binding sites of Src-homology-2 (SH2) and phosphotyrosine binding (PTB) domaincontaining molecules [18]. DDR1 is often overexpressed in cancer, and plays a critical role in cancer cell migration, EMT, and metastases [19-22]. We recently reported that, in breast cancer cells, IGF-1R functionally crosstalks with DDR1 and this interaction increases IGF-1R stability and enhances protumorigenic actions of IGF-1 [23]. In turn, IGF-1, as well as IGF-2 and insulin, induce DDR1 upregulation and activation establishing a positive feedback of IIGFs [24].

In the present work we aimed at elucidating the biological role of the IR - DDR1 crosstalk in human breast cancer cells. These results indicate that this functional interaction plays a significant role in human breast cancer and may become a viable target for therapy.

\section{RESULTS}

\section{DDR1 and IR expression in breast cancer cells}

We first evaluated by immunoblot the expression of DDR 1 and IR in a panel of human breast cancer cell lines (MCF-7, T47D, ZR-75, BT-474, MDA-MB-157, MDAMB-231, MDA-MB-468). Both molecules were expressed at variable levels with the highest DDR1 levels observed in MCF-7, T47D, ZR-75, BT-474 and MDA-MB-468, and the highest IR levels observed in MCF-7, ZR-75 and
MDA-MB-157 cells (Figure 1a). DDR1 and IR mRNA expression, measured by quantitative real-time RT-PCR (qRT-PCR), was generally in good agreement with the immunoblot results (Figure $1 \mathrm{~b}$ ).

MCF-7, BT-474 and MDA-MB-157 breast cancer cells were chosen for subsequent experiments. All these cells have ductal characteristics and metastatic potential, and all respond to insulin [25]. MCF-7 and BT-474 are estrogen receptor positive, while MDA-MB-157 cells have characteristics of triple negative cells. BT-474 cells are also HER-2 positive and tamoxifen-resistant. Both MCF-7 and BT-474 cells expressed high levels of DDR1 and IR, with MCF-7 expressing higher IR levels than BT-474. MDA-MB-157 showed low levels of DDR1 and intermediate levels of IR. The IGF-1R was expressed at high levels in MCF-7 cells, low levels in MDA-MB-157 and intermediate levels in BT-474 cells (Figure 1a).

\section{DDR1 and IR interact in breast cancer cells}

In order to evaluate whether the DDR1 and IR colocalize in breast cancer cells, MCF-7 cells were plated onto coverslips, serum-starved for $24 \mathrm{~h}$ and stimulated with either insulin or IGF-2 at a dose of $10 \mathrm{nM}$ for 5 and 20 min. Cells were then stained with anti-DDR1 and antiIR antibodies and examined by confocal microscopy. In unstimulated cells, IR and DDR1 were mainly expressed at the plasma membrane with minimal co-localization observed. After cell stimulation with either insulin (Figure 2a, upper panel) or IGF-2 (Figure 2a, lower panel), both IR and DDR1 were rapidly internalized and co-localized in both the cytoplasm and perinuclear compartments. These results were confirmed by coimmunoprecipitation. MCF-7 cells were serum starved, treated or not with either insulin or IGF-2 (10nM for $5 \mathrm{~min}$ ), lysed and immunoprecipitated with anti-DDR1 antibody. Immunoprecipitates were then blotted with either anti-DDR1 or anti-IR antibodies, respectively (Figure 2b). DDR1 co-precipitated with the IR and this interaction was enhanced after insulin and IGF-2 stimulation (Figure 2b).

\section{DDR1 expression levels regulate insulin and IGF-2 biological effects}

We next evaluated whether DDR1 expression could modulate the biological effects of insulin and IGF-2 in breast cancer cells. Indeed, in all three breast cancer cell lines, MCF-7, MDA-MD-157 and BT-474, DDR1 silencing by a pool of four specific siRNA oligos (Figure 3a) was associated with marked inhibition of cell viability as assessed by the MTT assay (Figure 3b) and cell cycle progression (Figure 3c), both in unstimulated cells and after treatment with either insulin or IGF-2. DDR1 silencing additionally inhibited other protumorigenic actions of insulin and IGF-2, such as cell invasion 
a

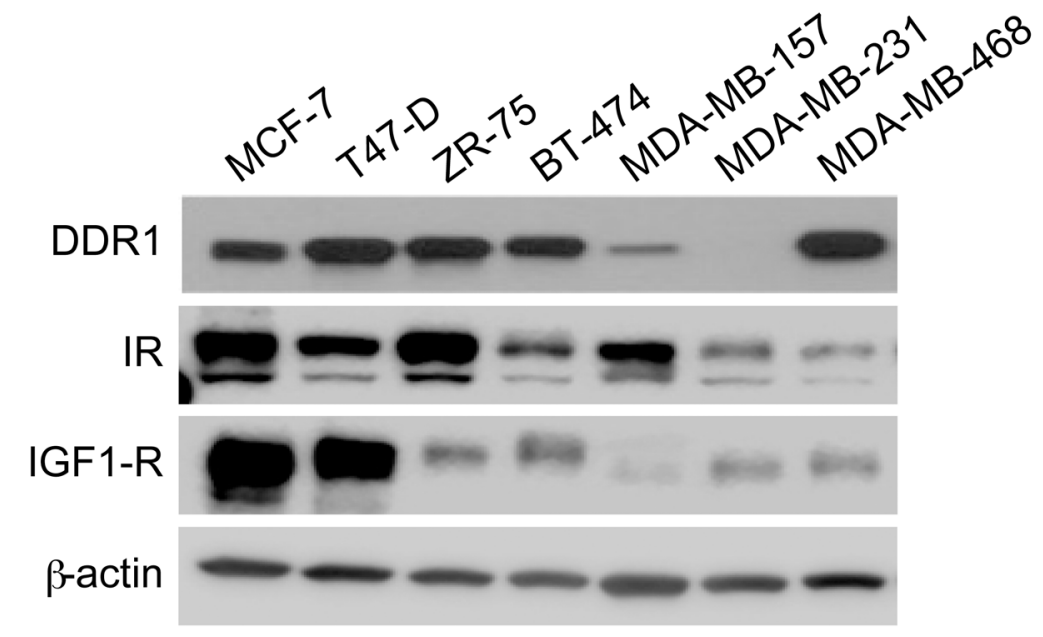

b

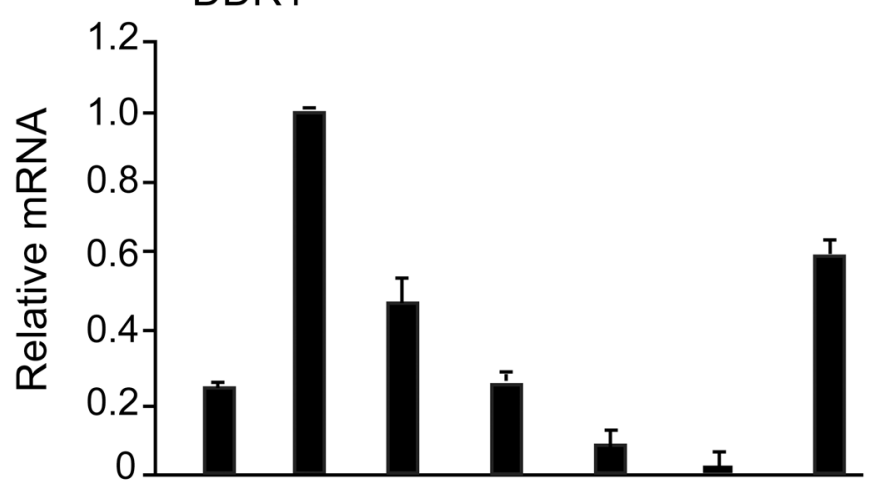

IR

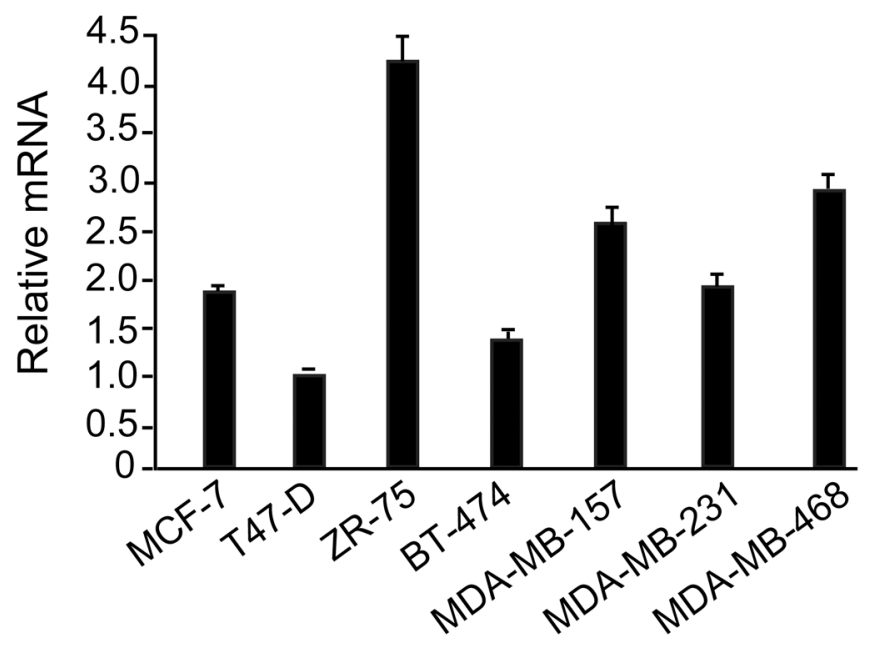

Figure 1: IR, DDR1 and IGF-1R expression in cultured cells. (a) DDR1, IR and IGF-1R protein expression in various cell lines. A panel of human breast cancer cell lines (MCF-7, T47-D, ZR-75, BT-474, MDA-MB-157, MDA-MB-231, MDA-MB-468) were analyzed by western immunoblot for DDR1, IR and IGF-1R expression using specific polyclonal antibodies, as indicated. $\beta$-actin antibody was used as control for protein loading. A representative blot of three independent experiments is shown. (b) qRT-PCR analysis of DDR1 and IR mRNA. Human DDR1 and IR mRNA levels were evaluated in all human cell lines shown in panel (a). Normalization was done using human $\beta$-actin as housekeeping control gene. Data are presented as the mean \pm SEM (error bars) from three independent experiments. 

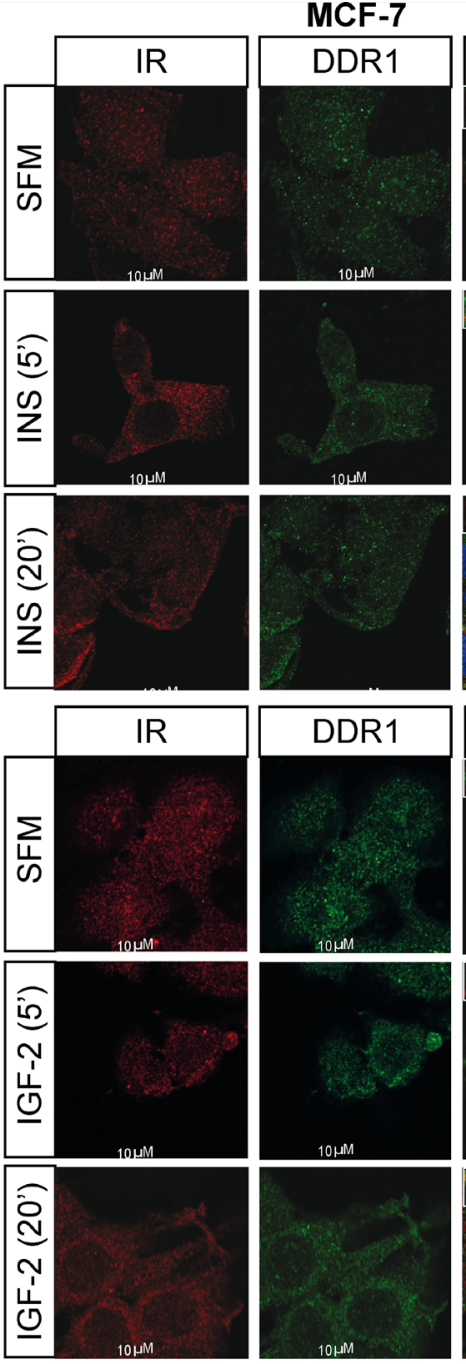

b

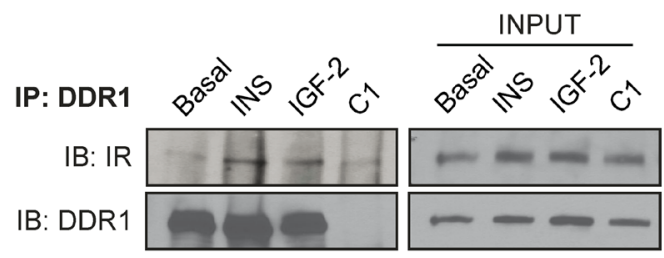

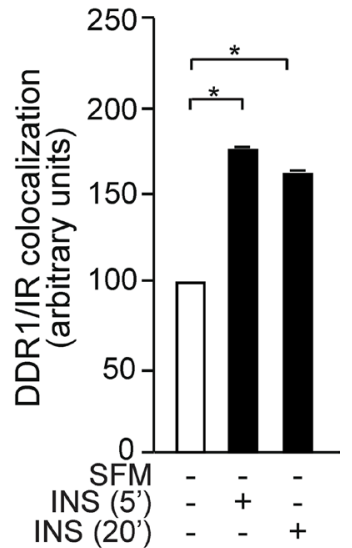
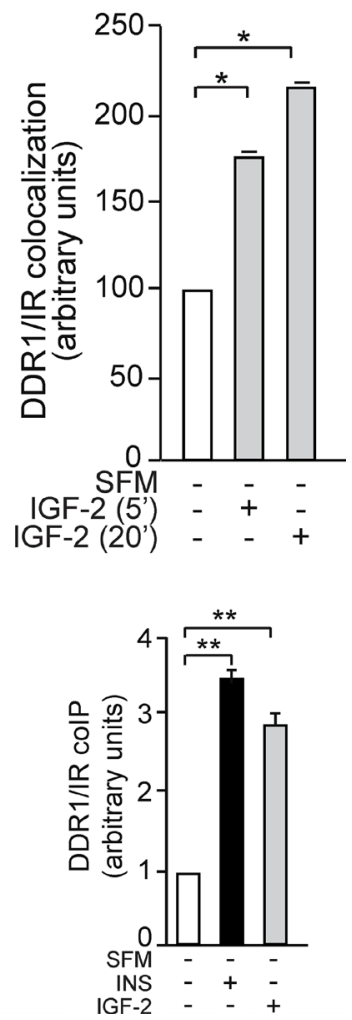

Figure 2: IR and DDR1 co-localization. (a) IR and DDR1 co-localize in breast cancer cells. MCF-7 cells were plated onto coverslips and serum-starved for $6 \mathrm{~h}$. Cells were then stimulated with 10nM of either insulin (upper panel) or IGF-2 (lower panel) for the indicated times. The staining indicating co-localization of the IR with DDR1 was assessed by confocal microscopy. Graphs on the right showing the co-localization index, calculated by ImageJ software, represent the mean \pm SEM of two independent experiments. (b) IR and DDR1 coimmunoprecipitate in MCF-7 breast cancer cells. Insulin and IGF-2 stimulation increases IR co-immunoprecipitation with DDR1. Cells were serum starved for $24 \mathrm{~h}$ and stimulated with either insulin or IGF-2 (10nM) for $5 \mathrm{~min}$. Cells were then solubilized and total lysates were (C1). Immunoprecipitated with anti-DDR1 specific antibody. Negative control, including the use of an unrelated primary antibody, is also shown. An aliquot of each fraction (input) was evaluated as control. Filters were probed with anti-DDR1 or anti-IR antibodies, as indicated. A representative blot of three independent experiments is shown. The graph on the right represents the mean \pm SEM of the densitometric analysis where IR signal was normalized against total DDR1. (a-b) $* 0.01<\mathrm{p}<0.05 ; * 0.001<\mathrm{p}<0.01$; (basal vs. insulin or IGF-2). Statistical significance was calculated using Student's t-test. 


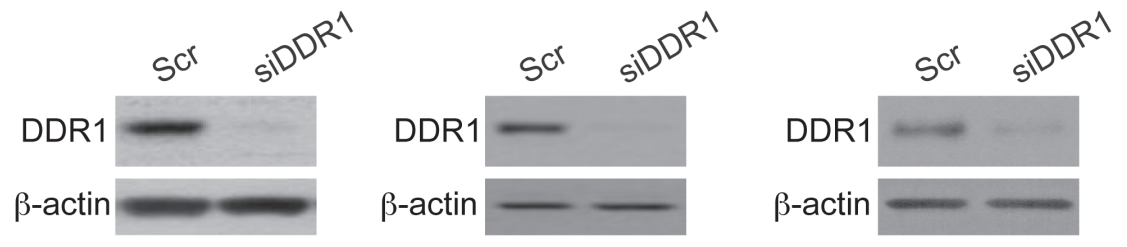

b

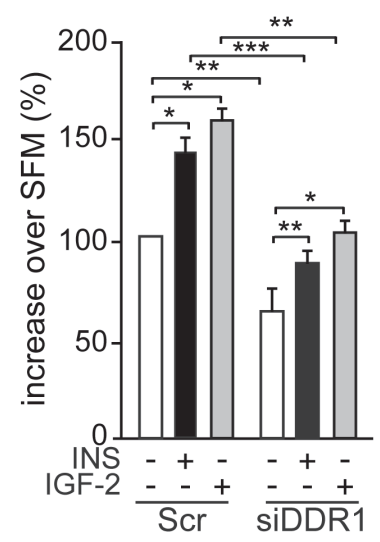

C

c Cell cycle

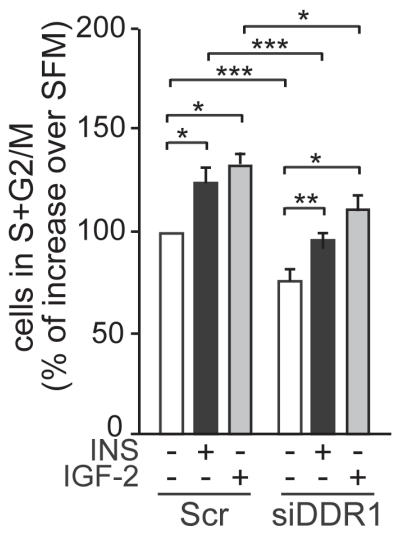

\section{Proliferation}
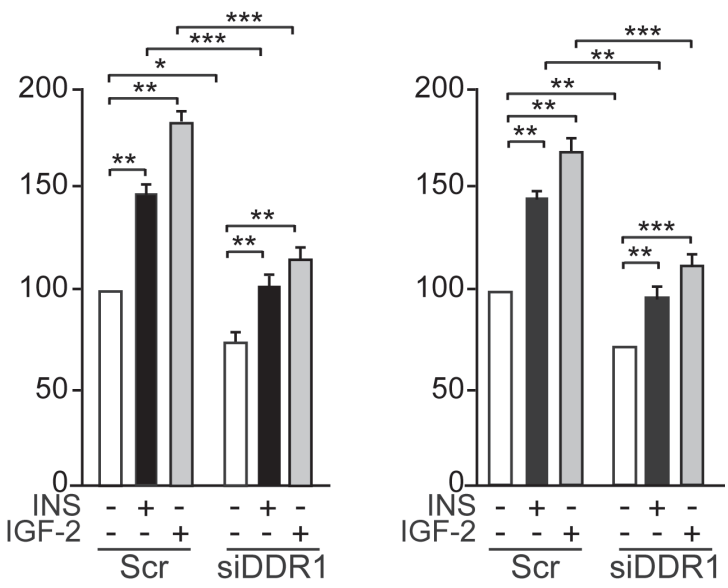

Figure 3: DDR1 depletion affects insulin and IGF-2 mediated biological effects in human cancer cells. (a) Western blot before and after DDR1 depletion. MCF-7, MDA-MB-157 and BT-474 breast cancer cells were transiently transfected with either a pool of four DDR1 siRNA oligos or scramble siRNA oligos. After $24 \mathrm{~h}$, cells were grown in medium containing $2.5 \%$ of CS-FCS for $24 \mathrm{~h}$. DDR1 depletion was confirmed for each cells line by western blot analysis as shown in the panel. (b) Cell proliferation. Cell viability was evaluated by MTT assay. Values are expressed as percentages of untreated scramble-transfected cells (basal) and represent the mean \pm SEM of three independent experiments in triplicate. (c) Cell cycle progression. MCF-7, MDA-MB-157 and BT-474 breast cancer cells were transiently transfected as in (a). After $24 \mathrm{~h}$, cells were grown in medium containing $0.1 \%$ of BSA for additional $24 \mathrm{~h}$. Cells were then incubated with or without insulin or IGF-2 at a dose of $10 \mathrm{nM}$ for additional $48 \mathrm{~h}$ and analyzed for cell-cycle profiles. Cell populations positive for propidium iodine staining were evaluated by FACS analysis, and G0/G1 and G2/M phases were scored. The graph shows the percentage of cells in S and G2/M phases. Values are expressed as percent of basal (untreated scramble transfected cells) and are the mean $\pm \mathrm{SEM}$ of three independent experiments.

(Continued) 


\section{d Invasion}

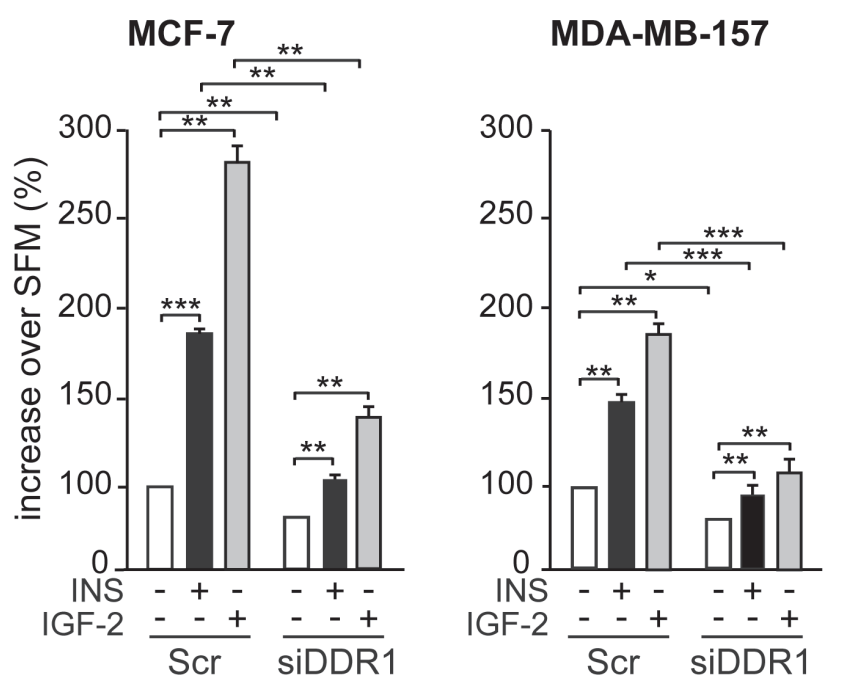

\section{BT-474}

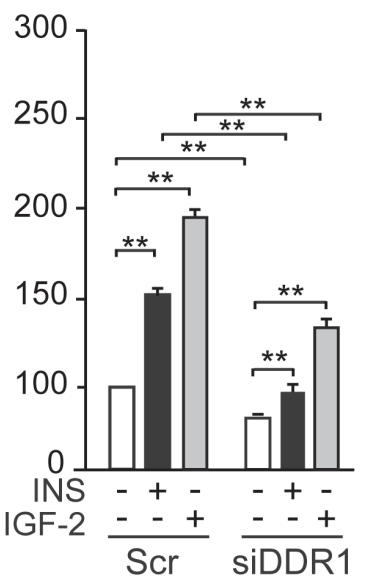

e Colony formation
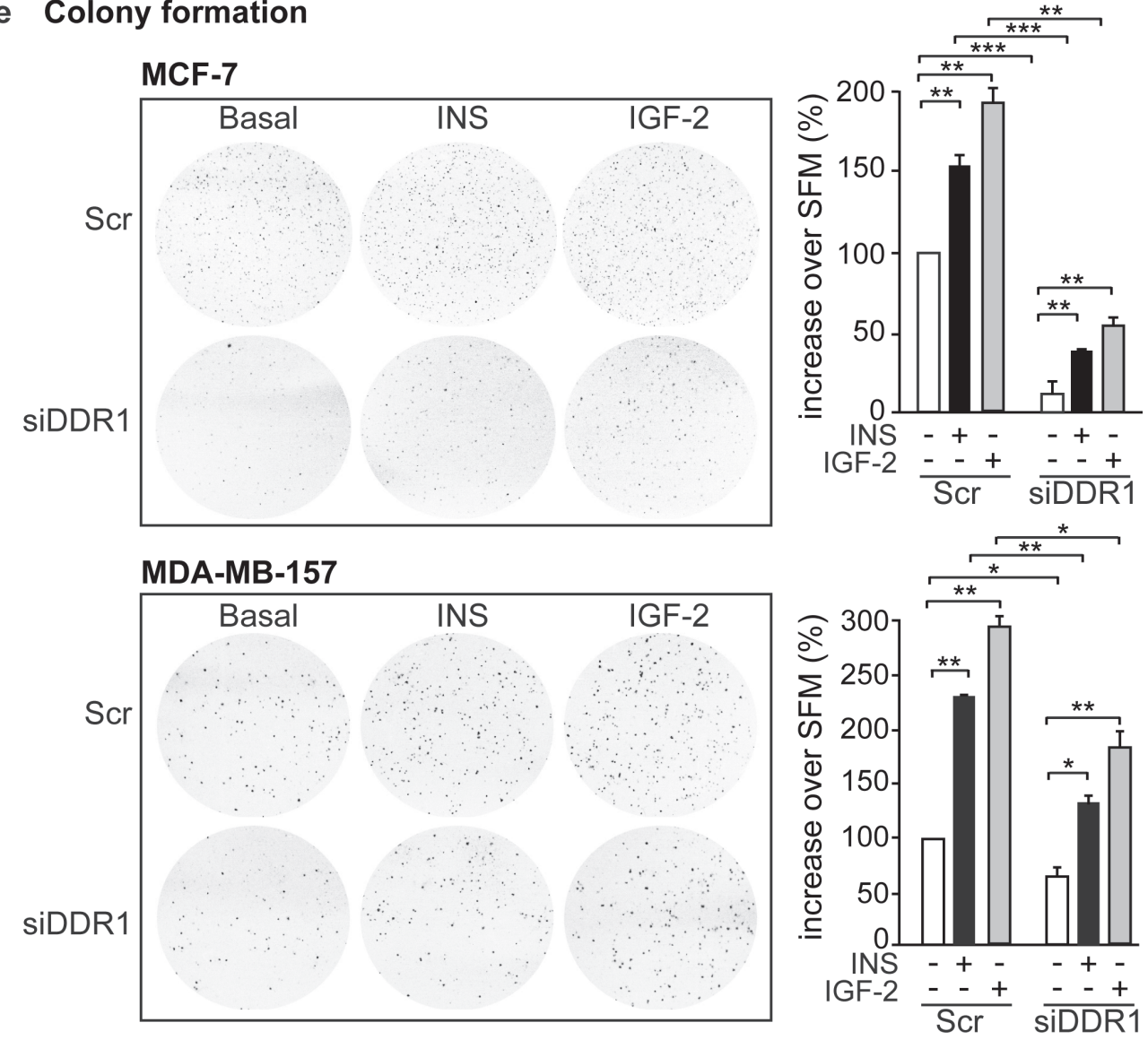

Figure 3: (Continued) (d) Cell invasion. MCF-7, MDA-MB-157 and BT-474 breast cancer cells were transiently transfected as in (a). After $24 \mathrm{~h}$, cells were grown in medium containing $0.1 \%$ of BSA for additional $24 \mathrm{~h}$. Cells were then removed from plates with $0.01 \%$ trypsin and seeded on polycarbonate filters coated with $25 \mu \mathrm{g} / \mathrm{mL}$ fibronectin. Cells were allowed to migrate for $6 \mathrm{~h}$ (MCF-7 and MDA-MB-157) or $8 \mathrm{~h}$ (BT-474 cells) in response to $10 \mathrm{nM}$ of insulin or IGF-2 added to the lower chamber. Values are mean \pm SEM of three independent experiments done in duplicate and are expressed as percent increase over untreated scramble cells (basal). (e) Colony formation. MCF-7, MDA-MB-157 and BT-474 breast cancer cells were transiently transfected as in (a), and seeded in soft-agar, as described in Materials and Methods. Cells were plated in triplicate and cultured in serum free medium containing 2.5\% CS-FCS for 3 weeks. Colonies developed only from plated MCF-7 and MDA-MB-157 cells but not from BT-474. Colonies were stained with MTT and then photographed. The histogram represents the mean number of colonies shown in (e). Error bars indicate SEM $(\mathrm{n}=3$ wells). $(\mathbf{b}-\mathbf{e}) * 0.01<\mathrm{p}<0.05 ; * * 0.001<\mathrm{p}<0.01$; $* * * \mathrm{p}<0.001$. Statistical significance was calculated using one-way ANOVA followed by Bonferroni test. 
through fibronectin-coated filters (Figure 3d) and colony formation in semi-solid agar (Figure 3e). Accordingly, transient DDR1 overexpression (Figure 4a) enhanced cell viability (Figure 4b), cell cycle progression (Figure 4c), cell invasion (Figure 4d), and colony formation (Figure $4 \mathrm{e}$ ), both in unstimulated cells and after stimulation with either insulin or IGF-2. In our experimental conditions, BT-474 cells did not form colonies in soft agar with charcoal-stripped serum-containing media.

Noteworthy, all these experiments were carried out in the absence of collagen, indicating that this modulation of insulin and IGF-2 effects is independent of DDR1 function as a collagen receptor.

\section{DDR1 is a critical regulator of IR expression and downstream signaling}

As DDR1 regulates IR biological actions, we evaluated whether DDR1 regulated IR expression levels and/or IR intracellular signaling after ligand stimulation. Indeed, DDR1 silencing by a pool of four specific siRNA oligos significantly reduced the expression of IR protein and mRNA (Figure 5a) in all three cell lines tested. Conversely, transient DDR1 overexpression using a constitutive DDR1 encoding vector (pCMV6DDR1) resulted in significant increase of IR protein and mRNA levels (Figure 5b). The increase in IR protein expression was further confirmed transiently transfecting MCF-7, MDA-MB-157 and BT-474 cell lines with pTZ doxy-inducible lentiviral vector encoding for DDR1 (Supplementary Figure 1). Accordingly, IR downstream signaling in response to insulin and IGF-2 stimulation was inhibited by DDR1 silencing (Figure 6a) and increased by DDR1 overexpression (Figure 6b). In particular, the two main IR downstream signaling cascades, the AKT and ERK1/2 pathways, were significantly affected by changes in DDR1 expression (Figure 6a and 6b).

Taken together these data indicate that DDR1 modulates IR response to insulin and IGF-2 by regulating IR expression levels.

\section{DDR1 regulates IR expression at multiple levels}

As DDR1 enhanced both IR mRNA and protein expression levels, we explored the mechanisms responsible for this effect. We first evaluated $26 \mathrm{~S}$ proteasome-dependent IR protein degradation. We found that the decrease in IR protein levels induced by DDR1 silencing was partially reversed after treating MCF-7 cells with the $26 \mathrm{~S}$ proteasome inhibitor, MG132 (Figure 7a). Next, we tested the contribution of the lysosomal degradation pathway by using the lysosomal inhibitor cloroquine. We found that, DDR1 levels were affected by cloroquine treatment in scramble-transfected cells, but not after DDR1 silencing (Figure 7b). Taken together, these results indicate that DDR1 affects the intracellular pool of
IR protein degraded via proteasome but not by lysosomal degradation.

As DDR1 additionally affected the steady-state level of IR mRNA (Figure 5a and 5b), we asked whether translational and/or transcriptional mechanisms were involved. To this aim we studied MCF-7 cells at different time points after treatment with either the protein synthesis inhibitor cycloheximide or the transcriptional inhibitor actinomycin D. We found that cycloheximide significantly prolonged IR protein half-life in cells transiently overexpressing DDR1 as compared to control cells (EV transfected). Indeed, in DDR1 overexpressing cells IR up-regulation was not affected by $24 \mathrm{~h}$ of cycloheximide treatment; in contrast, in control cells IR protein levels decreased to roughly $50 \%$ after $16 \mathrm{~h}$ exposure to cycloheximide, suggesting that DDR1 increases IR protein by additionally affecting its de novo synthesis (Figure 7c). Similarly, actinomycin D treatment reduced IR mRNA more markedly in control cells (EV) than in DDR1transfected cells; after $4 \mathrm{~h}$ exposure to the drug IR mRNA levels were $60 \%$ of basal in EV transfected cells vs. $20 \%$ in DDR1 overexpressing cells (Figure 7d).

We next evaluated whether DDR1 could affect the main factors involved in the regulation of $I R$ gene transcription, namely Sp1 and HMGA1, that are positive regulators, or $\mathrm{p} 53$, that is instead a negative regulator [26, 27]. Using MCF-7 cells, we found that IR down-regulation observed after DDR1 silencing was associated with significant reduction of $\mathrm{Sp} 1$ and HMGA1 proteins, and increased levels of p53 protein (Figure 8a). Conversely, IR upregulation observed after DDR1 transient overexpression was associated with opposite changes in Sp1, HMGA1 and p53 proteins (Figure $8 b$ ). The mRNA levels of these factors changed according to their protein expression profile both after DDR1 silencing (Figure 8c) or overexpression (Figure 8d). These data implicate DDR1 as a regulator of key transcription factors involved in IR gene expression.

Taken together, all these data indicate that DDR1 regulates IR expression at multiple levels by modulating protein degradation and stability, gene transcription and post-transcriptional mRNA regulation.

\section{DDR1 and IR are positively correlated in human breast cancer specimens}

In order to verify whether DDR1 and IR expression positively correlated in human breast cancer specimens we used a bioinformatic analysis. By computing Pearson correlation between three probes for DDR1 and IR, we obtained 228 Pearson values out of 288 possible combinations (60 Pearson values were not calculated because the probes were lacking for some datasets) (Supplementary Table 1). We found 99 statistically significant ( $p$-value $\leq 0.05$ ) positive Pearson values and 6 negative Pearson values. Interestingly, 6 datasets 

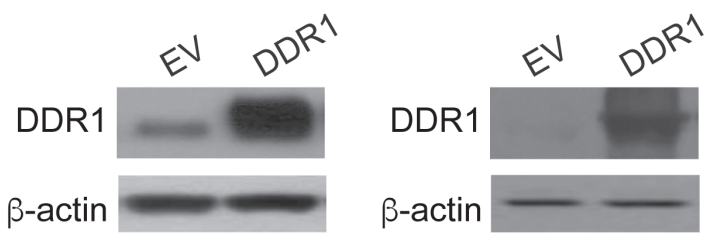

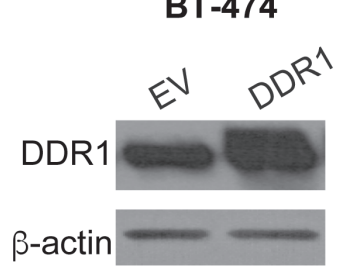

Proliferation
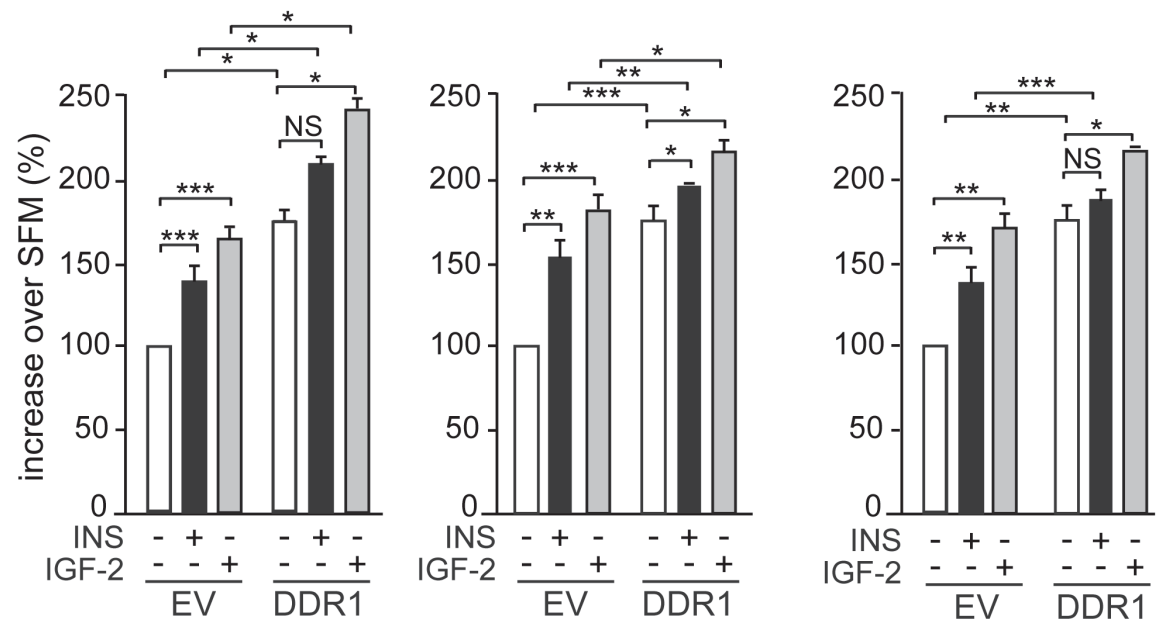

C

\section{Cell cycle}
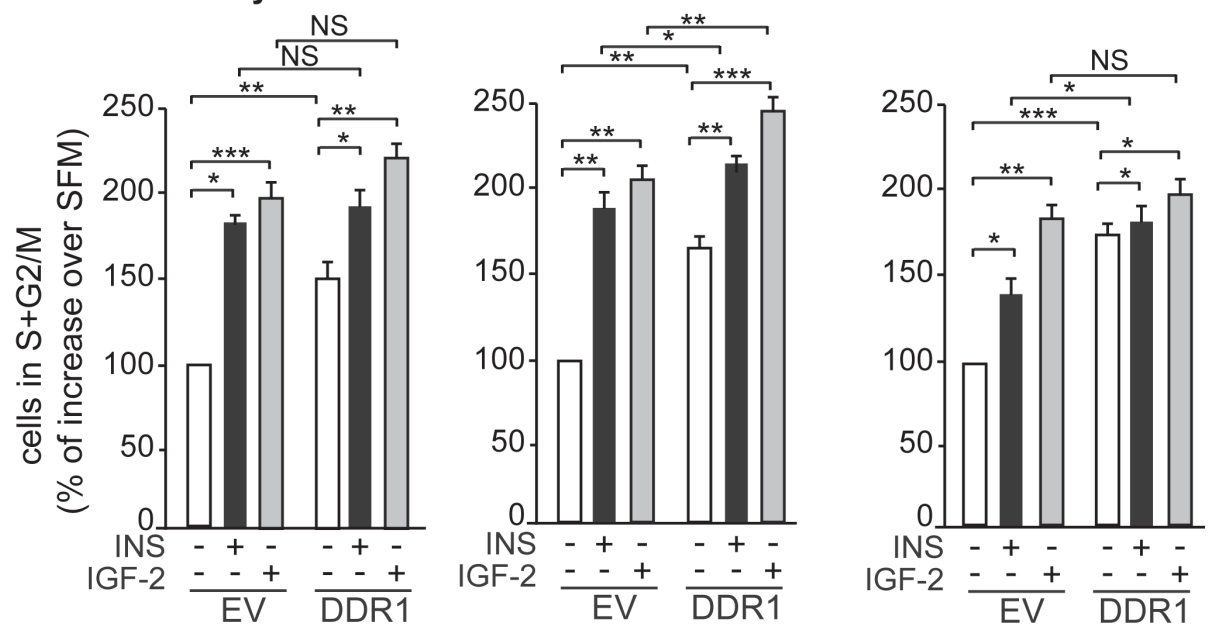

Figure 4: DDR1 overexpression affects insulin and IGF-2 mediated biological effects in human cancer cells. (a) Western blot before and after DDR1 overexpression. MCF-7, MDA-MB-157 and BT-474 breast cancer cells were transiently transfected with either constitutive empty (pCMV6-EV) or human DDR1 (pCMV6-DDR1) expressing vectors. After 24h, cells were grown in medium containing $2.5 \%$ of CS-FCS for 24h and then stimulated with 10nM of insulin or IGF-2. DDR1 overexpression was confirmed for each cells line by western blot analysis. (b) cell proliferation. Breast cancer cells were transfected as in (a). After $24 \mathrm{~h}$, cells were grown in medium containing $0.1 \%$ of BSA for additional $24 \mathrm{~h}$ and then stimulated with $10 \mathrm{nM}$ of insulin or IGF-2 for $48 \mathrm{~h}$. Cell viability was evaluated by MTT assay. Values are expressed as percentages of empty vector-transfected cells (basal) and represent the mean \pm SEM of three independent experiments in triplicate. (c) Cell cycle progression. MCF-7, MDA-MB-157 and BT-474 breast cancer cells were transiently transfected as in (a). After $24 \mathrm{~h}$, cells were grown in medium containing $0.1 \%$ of BSA for additional $24 \mathrm{~h}$. Cells were then incubated with or without insulin or IGF-2 at a dose of $10 \mathrm{nM}$ for additional $48 \mathrm{~h}$ and analyzed for cell-cycle profiles. Cell populations positive for propidium iodine staining were evaluated by FACS analysis, and G0/G1 and G2/M phases were scored. The graph shows the percentage of cells in $\mathrm{S}$ and $\mathrm{G} 2 / \mathrm{M}$ phases. Values are expressed as percent of basal (untreated scramble transfected cells) and are the mean $\pm \mathrm{SEM}$ of three independent experiments.

(Continued) 

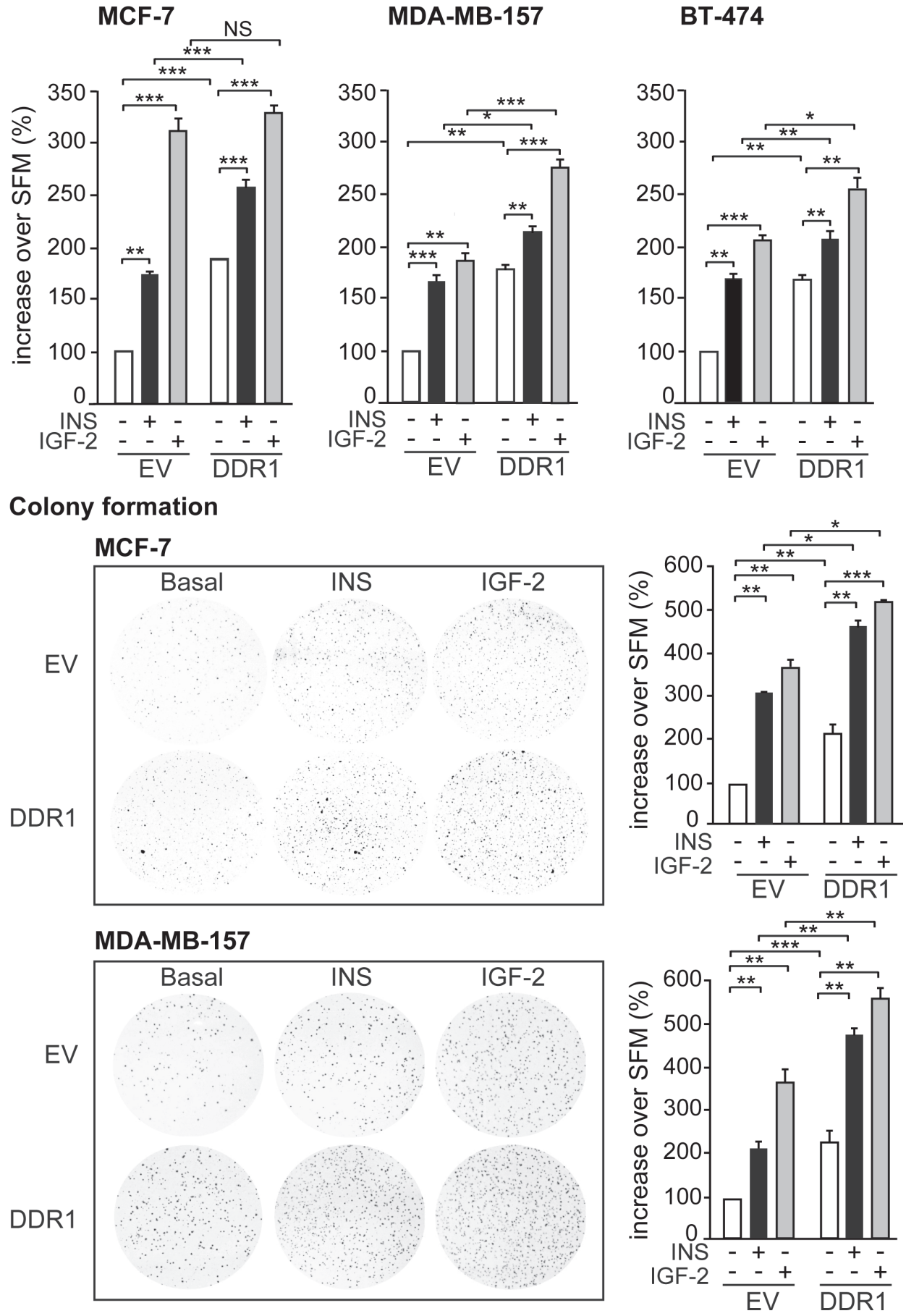

Figure 4: (Continued) (d) Cell invasion. MCF-7, MDA-MB-157 and BT-474 breast cancer cells were transiently transfected as in (a). After $24 \mathrm{~h}$, cells were grown in medium containing $0.1 \%$ of BSA for additional $24 \mathrm{~h}$. Cells were then removed from plates with $0.01 \%$ trypsin and seeded on polycarbonate filters coated with $25 \mu \mathrm{g} / \mathrm{mL}$ fibronectin. Cells were allowed to migrate for $6 \mathrm{~h}$ (MCF-7 and MDAMB-157) or $8 \mathrm{~h}$ (BT-474 cells) in response to $10 \mathrm{nM}$ of insulin or IGF-2 added to the lower chamber. Values are mean \pm SEM of three independent experiments done in duplicate and are expressed as percent of untreated scramble cells (basal). (e) Colony formation. MCF-7, MDA-MB-157 and BT-474 breast cancer cells were transiently transfected as in (a), were seeded in soft-agar, as described in Materials and Methods. Cells were plated in triplicate and cultured in serum free medium containing 2.5\% CS-FCS for 3 weeks. Colonies developed only from MCF-7 and MDA-MB-157 cells and not from BT-474. Colonies were stained with MTT and then photographed. The histogram represents the mean number of colonies shown in (e). Error bars indicate SEM ( $\mathrm{n}=3$ wells). (b-e) NS, *0.01<p $<0.05 ; \mathrm{p}>0.05 ; * * 0.001$ $<\mathrm{p}<0.01 ;{ }^{* * *} \mathrm{p}<0.001$; statistical significance was calculated using one-way ANOVA followed by Bonferroni test. 
a
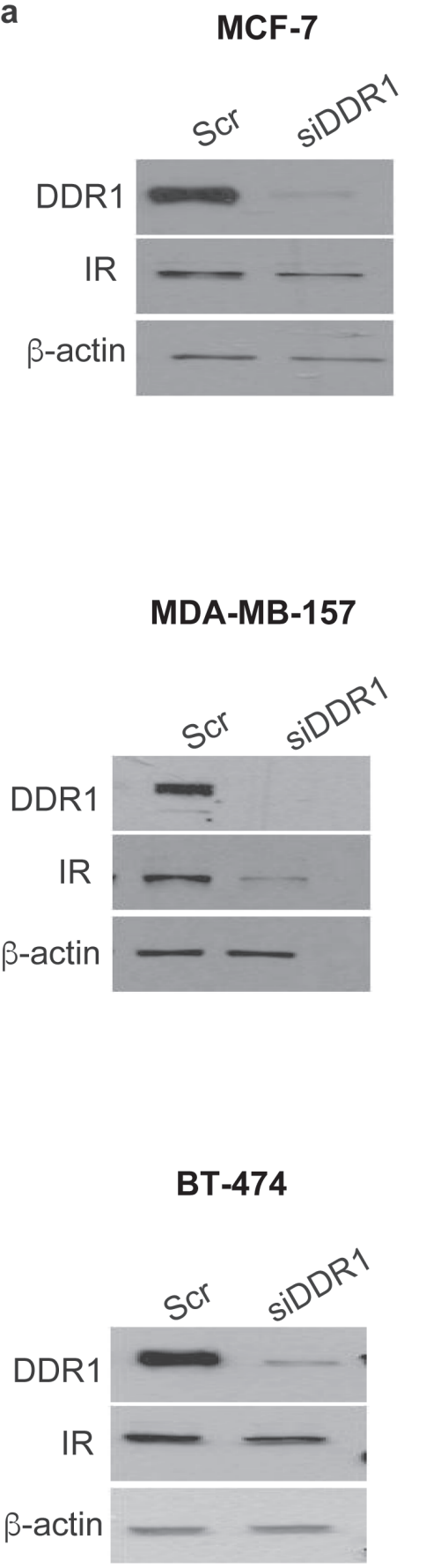
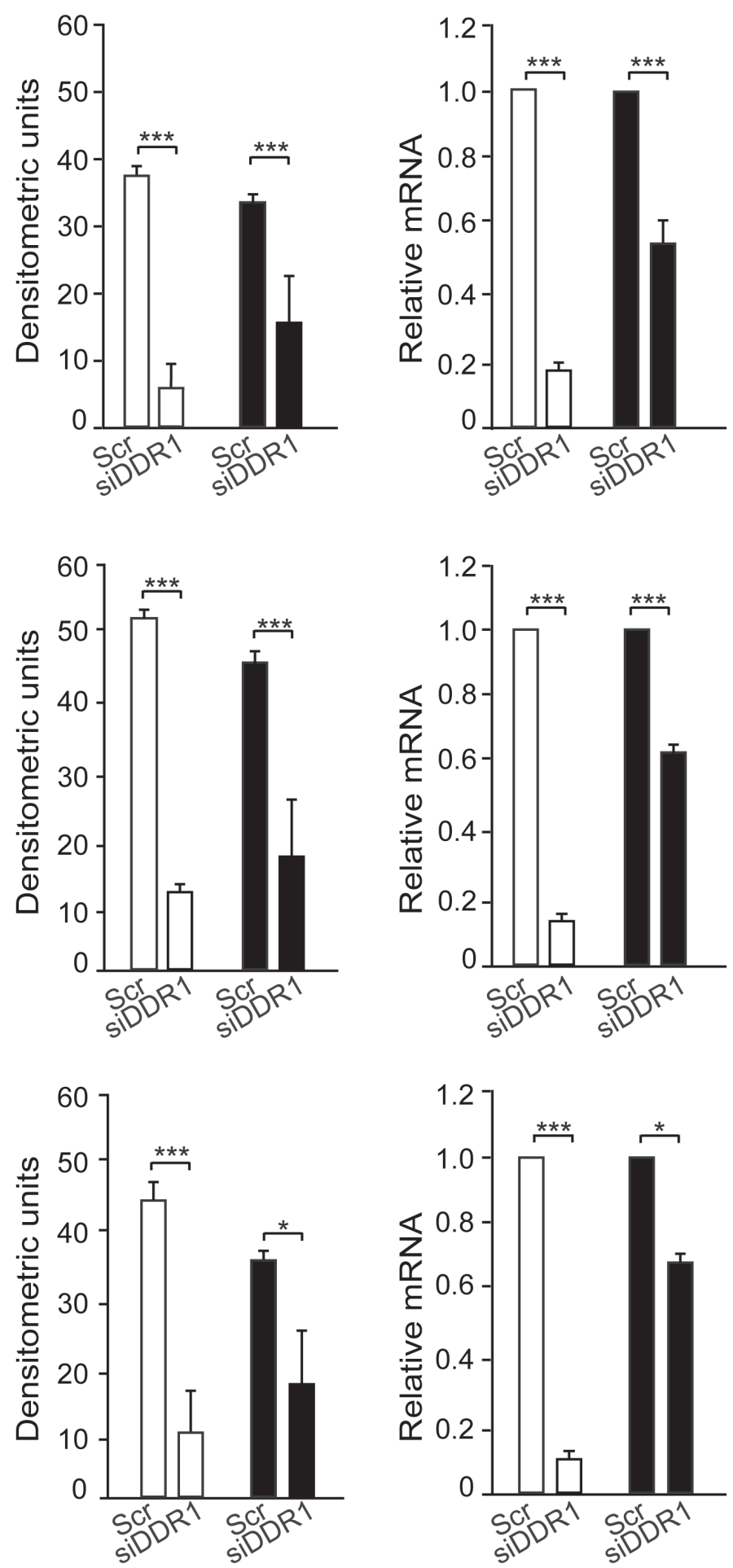

Figure 5: DDR1 affects IR expression. (a) IR protein and mRNA expression in DDR1-depleted cells. MCF-7, MDA-MB-157 and BT-474 breast cancer cells were transiently transfected with either a pool of four scramble or four DDR1 siRNA oligos. After 48h, cells were lysed and analyzed by SDS-PAGE and immunoblotted with the indicated primary antibodies. $\beta$-actin was used as control for protein loading. Blot is representative of three independent experiments. The histograms represent the mean $\pm \mathrm{SEM}$ of densitometric analysis after normalization against $\beta$-actin. In the same transfected cell lines, IR mRNA levels were evaluated by qRT-PCR analysis and values were normalized using human $\beta$-actin as housekeeping control gene. In parallel, DDR1 mRNA was evaluated by qRT-PCR to confirm DDR1 depletion (graphs on the right).

(Continued) 
b
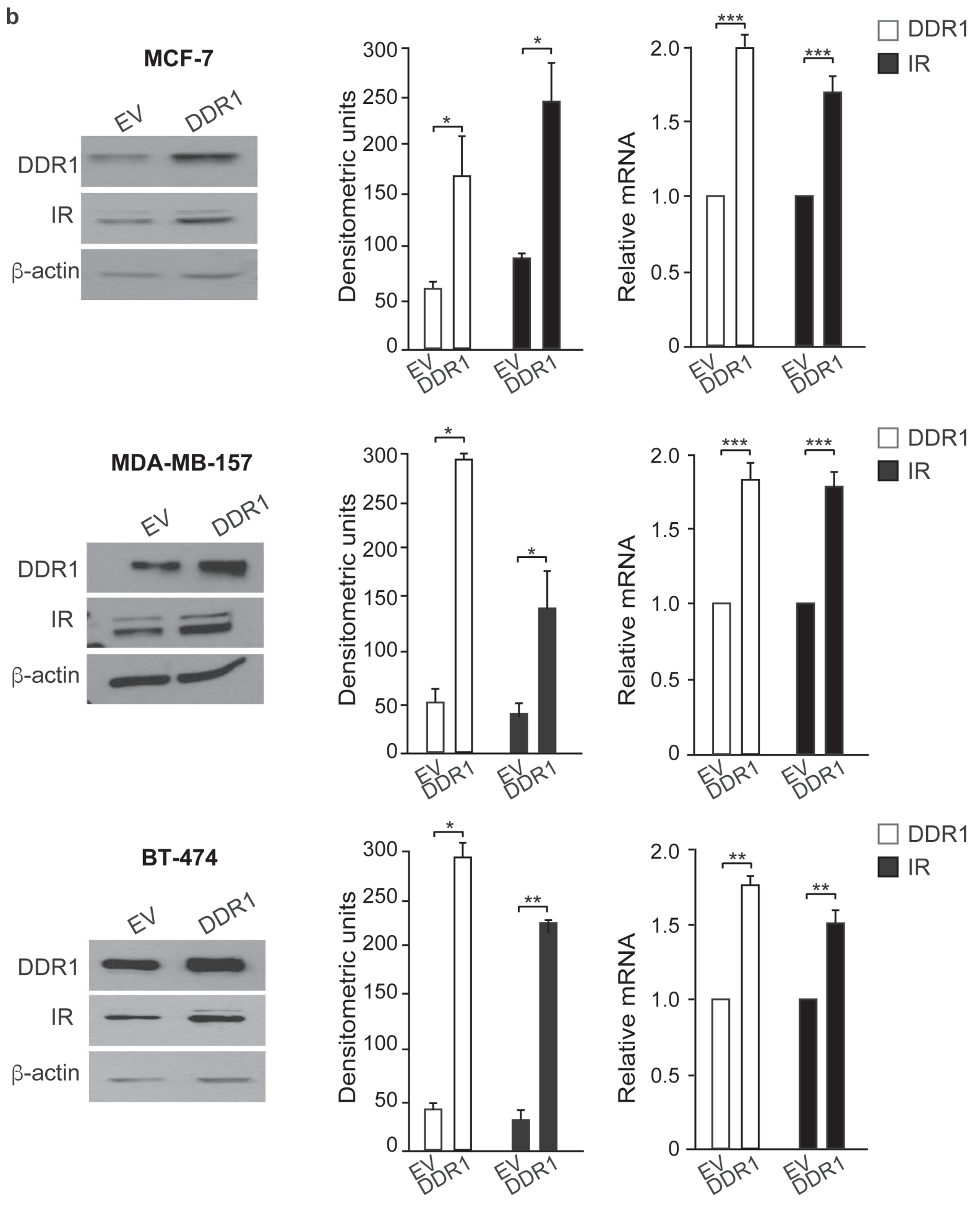

Figure 5: (Continued) (b) IR protein and mRNA expression after DDR1 overexpression. Breast cancer cells were transiently transfected with either constitutive empty (pCMV6-EV) or human DDR1 (pCMV6-DDR1) expressing vectors. After 48h, cells were lysed, analyzed by SDS-PAGE and immunoblotted with the indicated primary antibodies. $\beta$-actin was used as control for protein loading. The top panels show a representative blot of three independent experiments. The histograms represent the mean \pm SEM of densitometric analysis after normalization over $\beta$-actin. In the same transfected cells, IR mRNA levels were evaluated by qRT-PCR analysis and values were normalized using human $\beta$-actin as housekeeping control gene. The overexpression of DDR1 was confirmed measuring DDR1 mRNA by qRT-PCR (graphs on the right). (a-b) $* 0.01<\mathrm{p}<0.05 ; * 0.01<\mathrm{p}<0.05 ; * * 0.001<\mathrm{p}<0.01 ; * * * \mathrm{p}<0.001$; (scramble $v s$. siDDR 1 and EV vs. DDR1 and transfected cells). statistical significance was calculated using Student's t-test. 


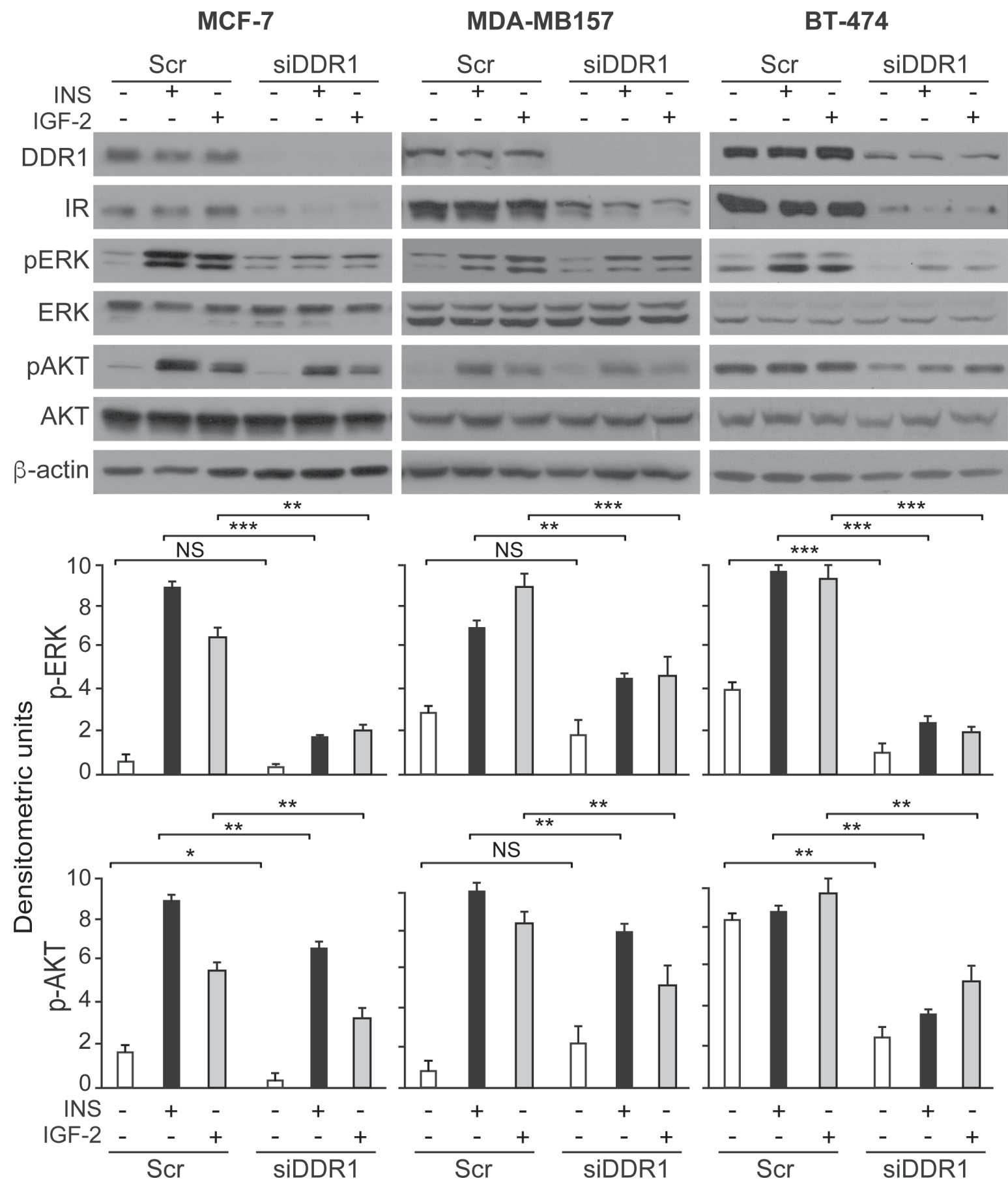

Figure 6: DDR1 depletion or overexpression affects insulin and IGF-2 downstream signaling in human breast cancer cells. (a) Insulin and IGF-2 signaling after DDR1 depletion. MCF-7, BT-474 and MDA-MB-157 breast cancer cells were transiently transfected with a pool of four scramble or of four siRNA oligos against DDR1. After 48h, cells were grown in medium containing $2.5 \%$ of CS-FCS for $24 \mathrm{~h}$ and then stimulated with or without $10 \mathrm{nM}$ of insulin or IGF-2 for 5 minutes. Cells were then lysed and analyzed by SDS-PAGE and immunoblotted with the indicated primary antibodies. $\beta$-actin was used as control for protein loading. The top panels show a representative of three experiments. The histograms represent the mean $\pm \mathrm{SEM}$ of densitometric analysis of three independent experiments after normalization of each phosphoprotein against $\beta$-actin.

(Continued) 

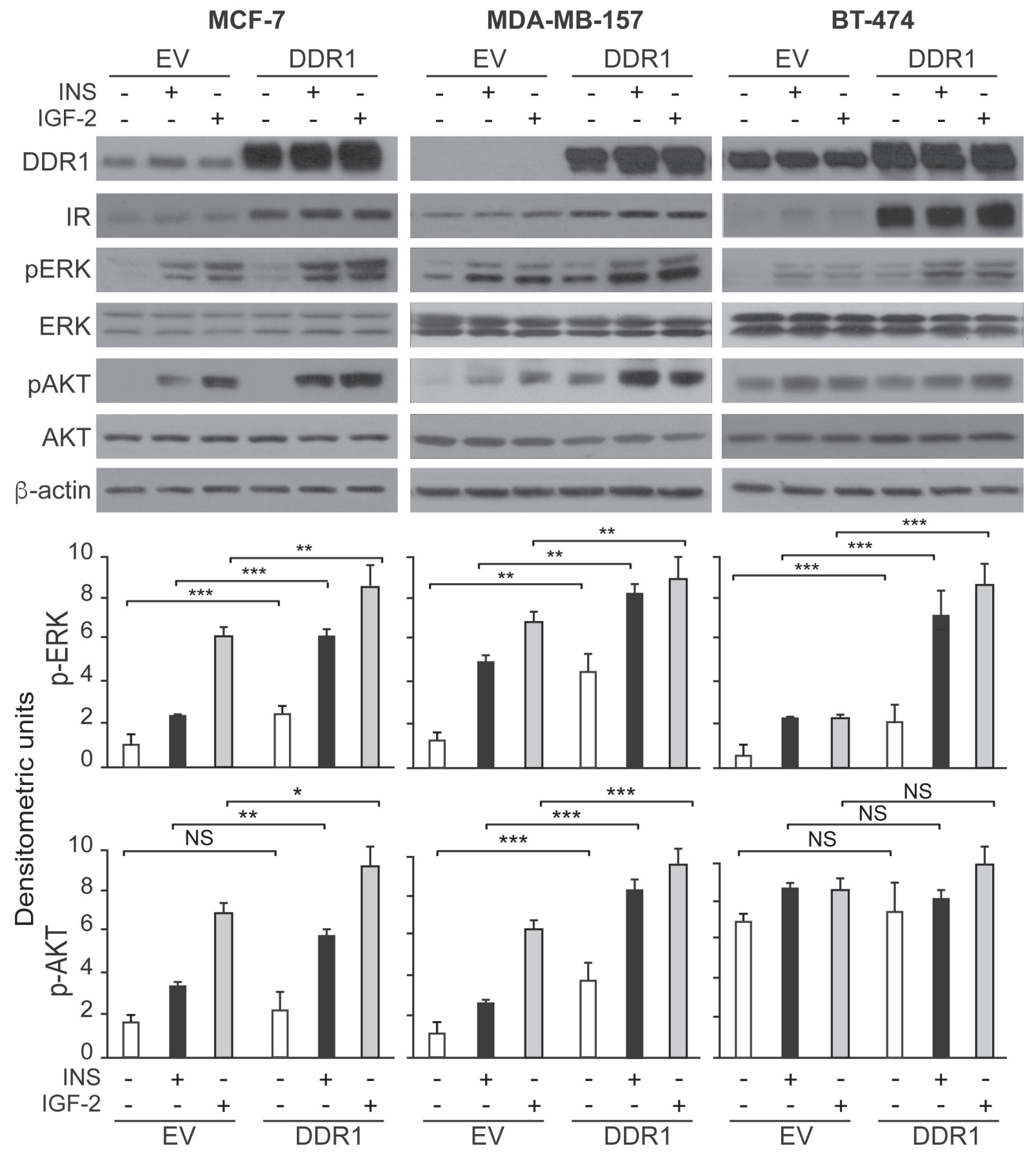

Figure 6: (Continued) (b) Insulin and IGF-2 signaling after DDR1 overexpression. MCF-7, BT-474 and MDA-MB-157 breast cancer cells were transiently transfected with plasmids encoding either the human DDR1 cDNA (pCMV6-DDR1) or the corresponding empty vector (pCMV6-EV). After 48h, cells were grown in medium containing $2.5 \%$ of CS-FCS for $24 \mathrm{~h}$ and then stimulated with or without $10 \mathrm{nM}$ of insulin or IGF-2 for 5 minutes. The activation of downstream signaling was assessed as in (a). Blots are representative of three independent experiments. The histograms represent the mean $\pm \mathrm{SEM}$ of densitometric analysis of three independent experiments after normalization of each phosphoproteins against $\beta$-actin. (a-b) NS, $p>0.05 ; * 0.01<\mathrm{p}<0.05 ; * * 0.001<\mathrm{p}<0.01 ; * * * \mathrm{p}<0.001$; statistical significance was calculated using one-way ANOVA followed by Bonferroni test. 
(gse21618, gse42568, gse12276, gse21653, gse29271, gse 76124) showed a persistent positive correlation between DDR1 and IR with all combinations of probes analyzed. Definitively, these computational data strongly suggested that a general positive correlation between DDR1 and IR transcripts exists in breast carcinoma (Supplementary Table 1).

For GEO datasets gse42568, gse21653, gse76124 we found clinical and biological information useful to stratify the data, in order to verify whether DDR1-IR correlation is associated with bio-pathological features of patients (Figure 9A and 9B). This analysis showed that correlation of expression was more statistically significant in tumors with the following characteristics: 1) negative for ER; 2) negative for progesterone receptor; 3) basallike histology; 4) positive for pathological lymph nodes; 5) positive for $\mathrm{Ki}-67$ protein status; 6) pathological tumor size 3 (pT3); 7) grade 3 (G3). The correlations a

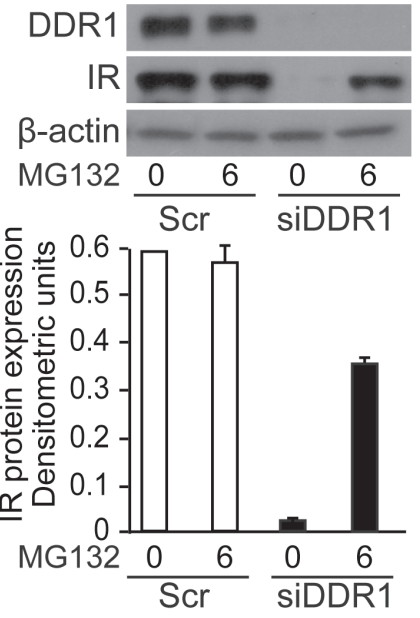

C
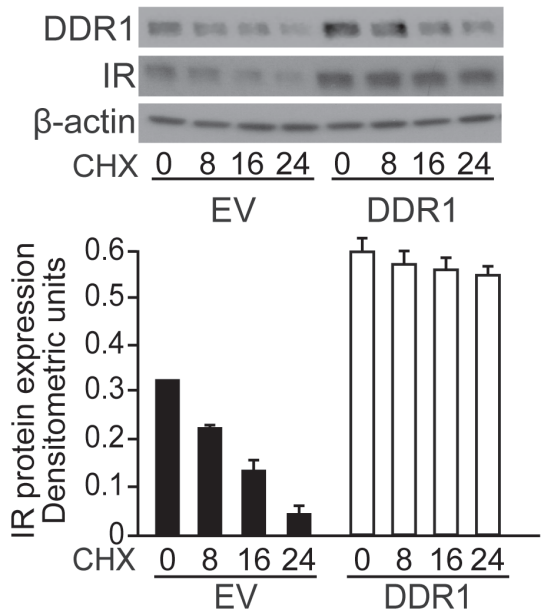

b

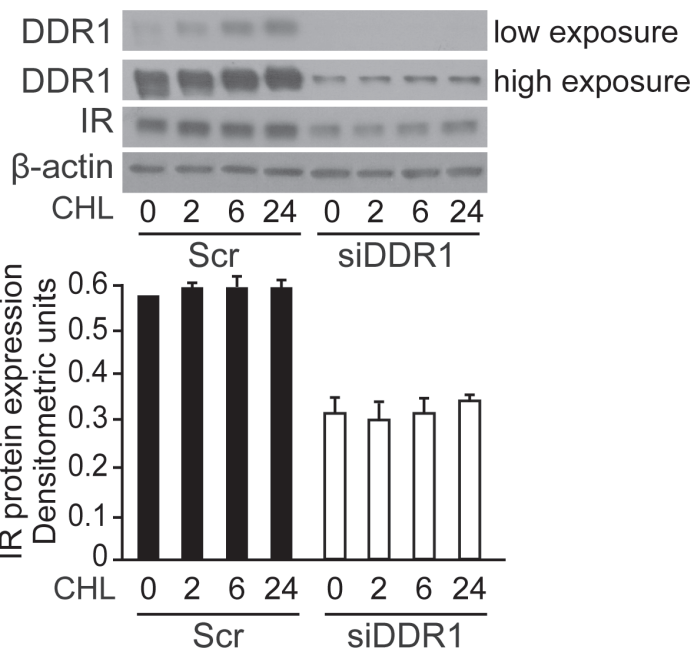

d

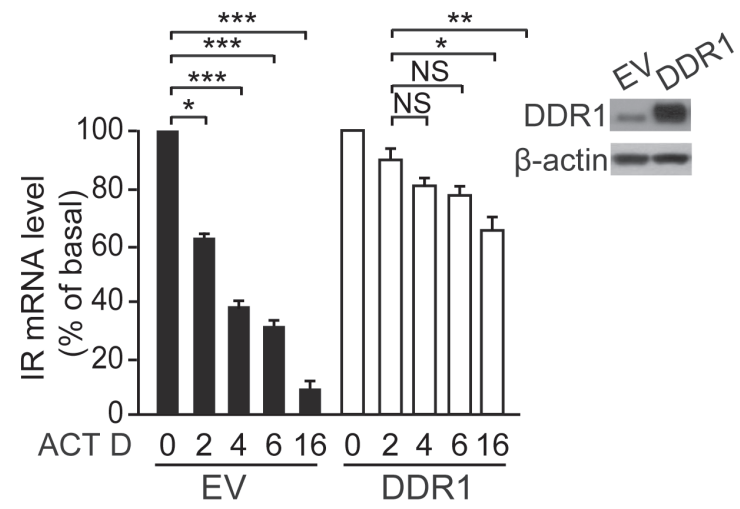

Figure 7: DDR1 stabilizes IR both at the protein and mRNA level in MCF-7 cells. (a) DDR1 depletion affects IR proteasomal degradation. MCF-7 cells were transiently transfected with either a pool of four scramble or four DDR1-specific siRNA oligos. After 48h, cells were treated with $1 \mu \mathrm{M}$ of the proteasome inhibitor MG132 for 6h. (b) DDR1 depletion does not affect IR lysosomal degradation. MCF-7 cells were transiently transfected as in (a). After $48 \mathrm{~h}$, cells were treated with $10 \mu \mathrm{M}$ of the cloroquine (CHL) for 2, 6, and 24h. (c) Cycloheximide treatment in DDR1 overexpressing cells. MCF-7 cells were transiently transfected with either pCMV6-EV or pCMV6-DDR1 encoding vectors. After $24 \mathrm{~h}$, cells were treated with $100 \mu \mathrm{M}$ of cycloheximide (CHX) for 8, 16, and 24h. (d) Actinomycin D treatment in DDR1 overexpressing cells. MCF-7 cells were transiently transfected as in (c). After $24 \mathrm{~h}$, cells were treated with $2.5 \mu \mathrm{g} / \mathrm{mL}$ of actinomycin D (ACT D) for 2, 4, 6, and 16h. IR mRNA levels were evaluated by qRT-PCR analysis and values were normalized using human $\beta$-actin as housekeeping control gene. DDR1 overexpression was confirmed by western blot analysis as shown on the right of the histogram. (a-c) Samples were analyzed by western blotting for DDR1 and IR expression. $\beta$-actin antibody was used as control. A representative blot of three independent experiments is shown. The histogram represents the mean $\pm \mathrm{SEM}$ of densitometric analysis after normalization against $\beta$-actin. (a-d) NS, p $>0.05 ; * 0.01<\mathrm{p}<0.05 ; *^{*} 0.001<\mathrm{p}<0.01 ; * * \mathrm{p}<0.001$. Statistical significance was calculated using Student's t-test. 
were statistically significant in both normal and tumor samples but $\mathrm{p}$-values were considerably lower in the latter, especially in poorly differentiated tumors (Figure 9B).

\section{DISCUSSION}

Our present results demonstrate that in human breast cancer cells DDR1 is a signaling partner of the IR and a strong modulator of IR expression and biological responses. DDR1 and IR co-localize and coimmunoprecipitate, especially after stimulation with either insulin or IGF-2. We also show that, after stimulation with insulin or IGF-2, DDR1 is rapidly internalized with the IR and co-localizes with the IR in the cytoplasm. These findings are reminiscent of similar data we previously observed with the IR-homolog IGF-1R [23]. Noteworthy,

a
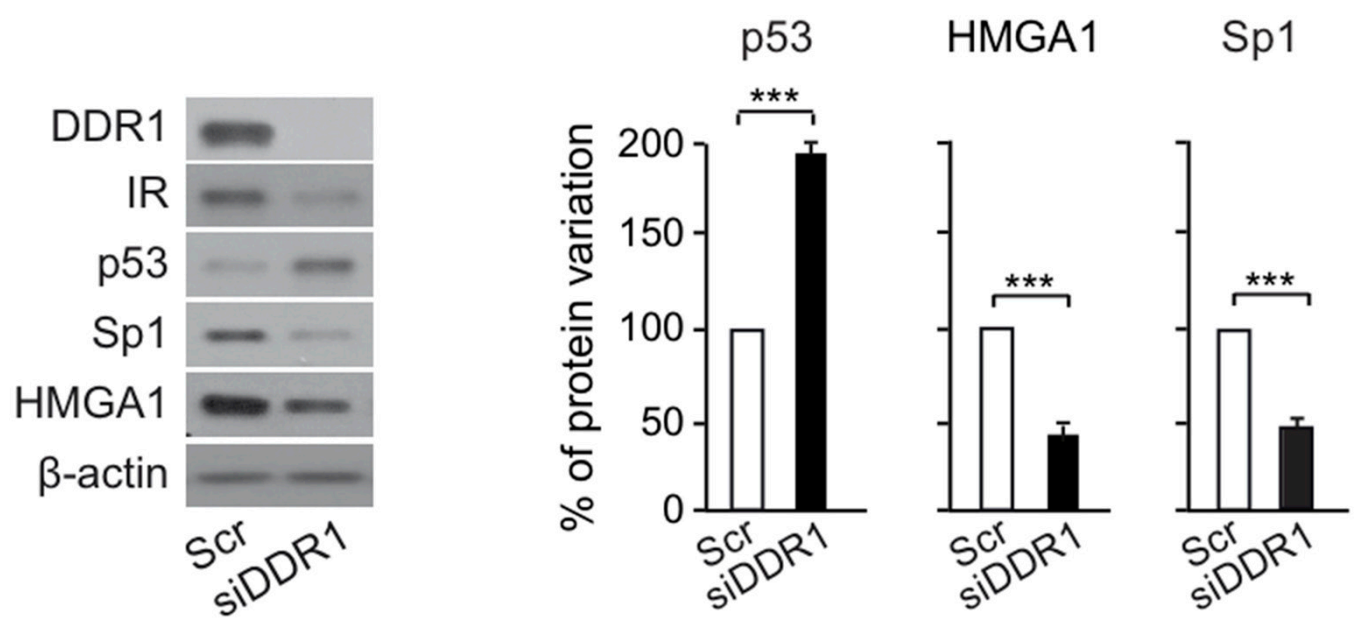

b

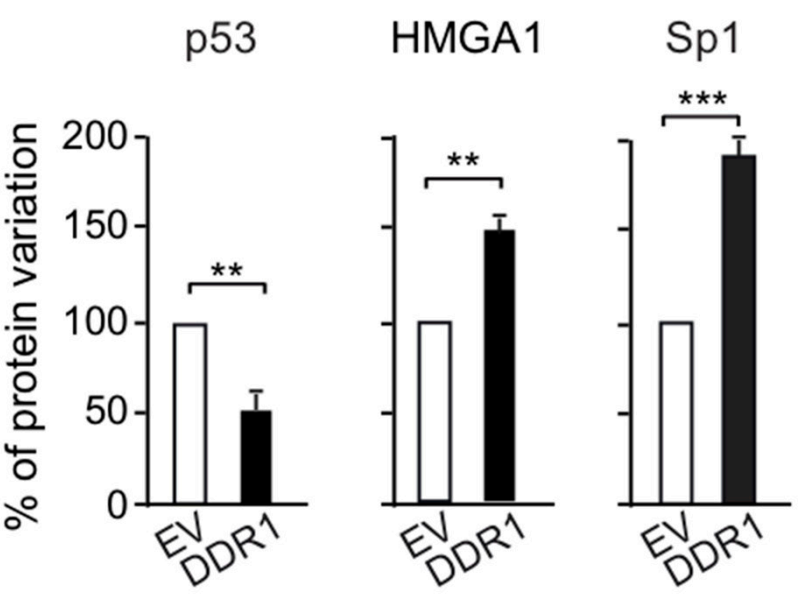

Figure 8: DDR1 affects IR - dependent transcription factors. (a) Protein levels of IR-dependent transcription factors after DDR1 depletion. MCF-7 breast cancer cells were transiently transfected with either a pool of four scramble or four DDR1 specific siRNA oligos. After 48h, protein expression of IR, and of p53, HMGA, and Sp1 transcription factors was evaluated by western blotting. The histograms represent the mean \pm SEM of densitometric analysis of three independent experiments after normalization against $\beta$-actin. (b) Protein levels of IR-related transcription factors after DDR1 overexpression. MCF-7 cells were transiently transfected with either either pCMV6-EV or pCMV6-DDR1 encoding vectors. After 48h, protein expression of IR, p53, HMGA, and Sp1 was evaluated by western blotting. The histograms represent the mean \pm SEM of densitometric analysis of three independent experiments after normalization against $\beta$-actin.

(Continued) 
C

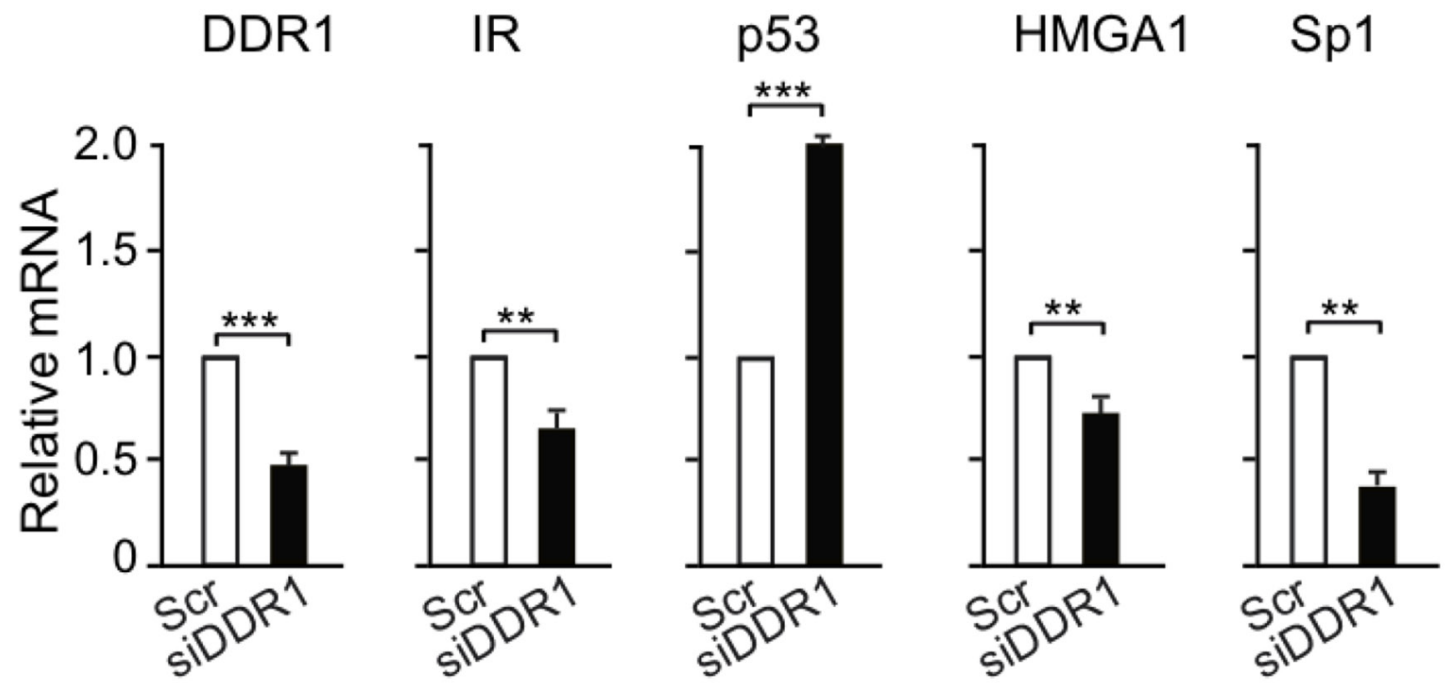

d

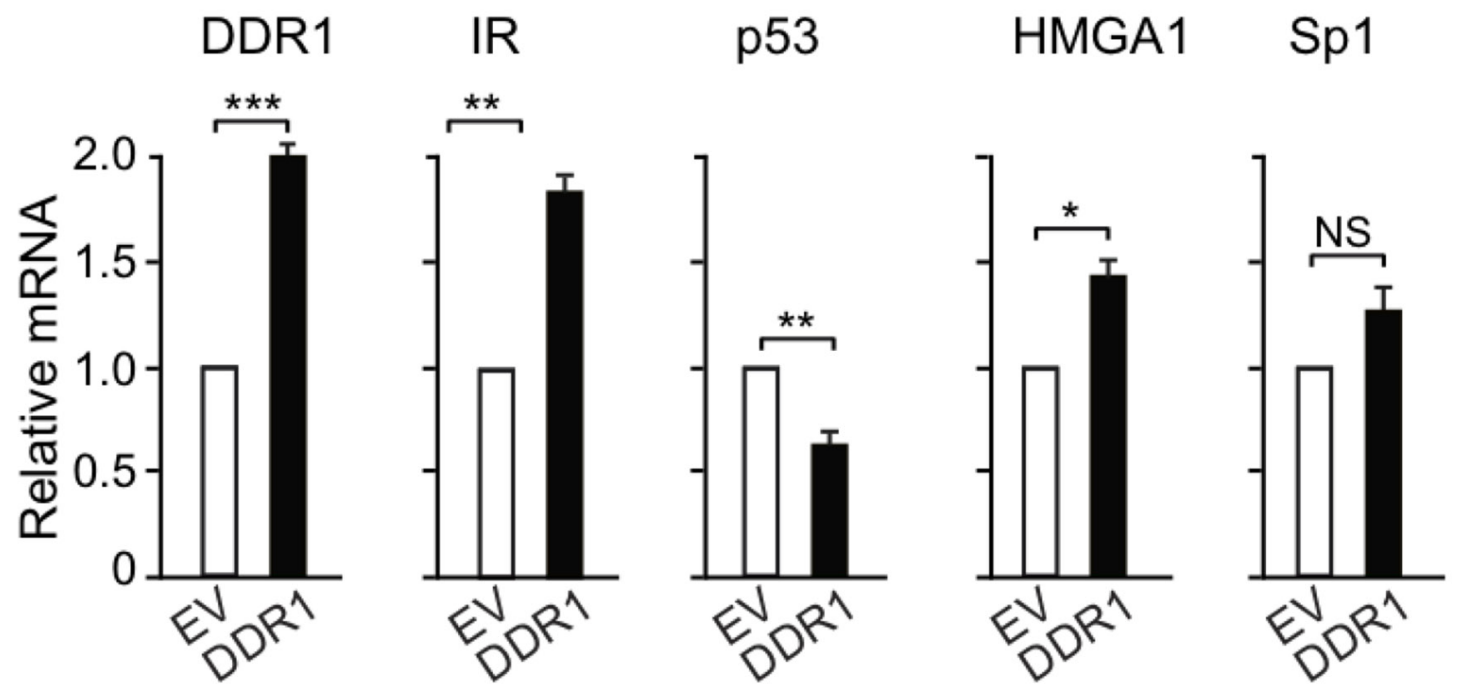

Figure 8: (Continued) (c) mRNA expression of IR-related transcription factors after DDR1 depletion. MCF-7 cells transfected as in (a) were evaluated by qRT-PCR analysis for IR, p53, HMGA, and Sp1 mRNA levels. Values were normalized using human $\beta$-actin as housekeeping control gene. DDR1 mRNA levels were also evaluated as control for DDR1 depletion efficiency. Values represent the mean \pm SEM of three independent experiments. (d) mRNA expression of IR-related transcription factors after DDR1 overexpression. In cells transfected as in (b), IR, p53, HMGA, and Sp1 mRNA levels were evaluated by qRT-PCR analysis and values were normalized using human $\beta$-actin as housekeeping control gene. DDR1 mRNA levels were also evaluated as silencing control. Values represent the mean \pm SEM of three independent experiments. (a-d) NS, p $>0.05 ; * 0.01<\mathrm{p}<0.05 ; * * 0.001<\mathrm{p}<0.01 ; * * * \mathrm{p}<0.001$. Statistical significance was calculated using Student's t-test. 
it has been demonstrated that DDR1 is internalized after binding to different forms of collagen (collagen I, IV and VI) $[16,18,28]$. Herein, we found that DDR1 cointernalization with IR is not dependent on collagen.

Remarkably, DDR1 modulates the two main signaling cascades downstream of the IR. DDR 1 silencing significantly reduced the phosphorylation of both AKT and ERK1/2 in response to insulin and IGF-2, while DDR1 overexpression enhanced it. According to these findings, DDR1 enhanced breast cancer cell proliferation, invasion and colony formation in response to insulin and IGF-2. Moreover, IR silencing abrogated the effect of DDR1 overexpression on cell viability and invasion, not only in response to insulin and IGF-2 but also in unstimulated cells, indicating that IR expression was pivotal for the effects of DDR1.
We found that a major mechanism by which DDR1 affects intracellular signaling and biological responses to insulin and IGF-2 is the modulation of IR expression. DDR1 affected IR expression at multiple levels by regulating both IR protein and mRNA half-life as well as transcription factors known to modulate IR gene expression [26, 27].

The decrease in IR protein levels induced by DDR1 depletion was sensitive to inhibitors of the proteasome but not to lysosomal inhibition. Collectively, these results suggest that DDR1 may preferentially regulate the intracellular pool of IR protein degraded via the proteasome, but it does not affect IR turnover dependent on lysosomal degradation.

Ubiquitination of tyrosine-kinase receptors, including the IGF-1R and IR [29-34], plays an important
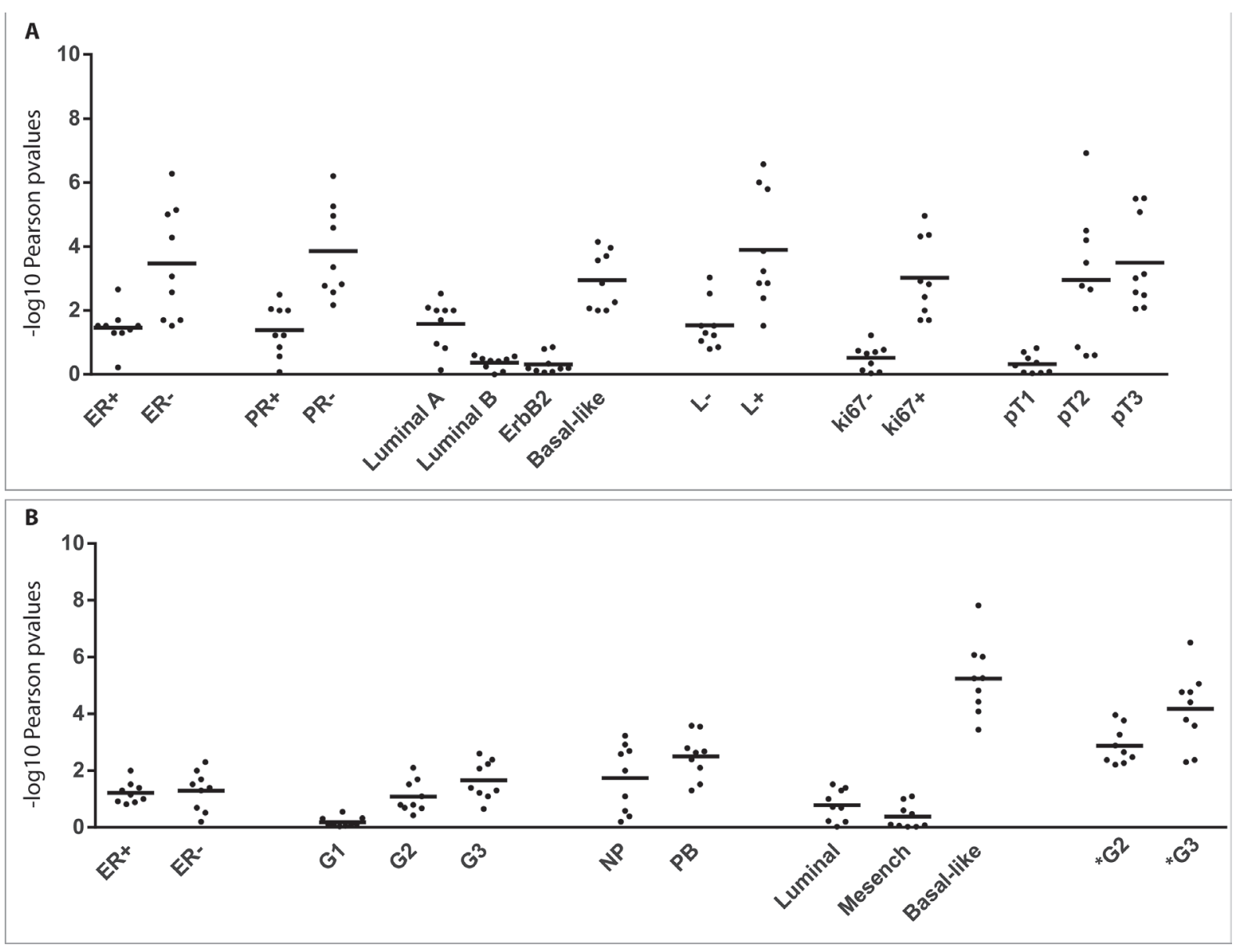

Figure 9: DDR1 correlates with IR in human breast cancer datasets. Stratification analysis of DDR1 and IR correlative expression was performed. Pearson tests were calculated by separating the patients in clinical classes. This analysis was computed for GEO datasets gse21653 (Panel A), gse42568, gse76124 (Panel B). Black dots showed nine different combinations of Pearson test for three DDR1 probes (1007_s_at, 210749_x_at, 207169_x_at) and three IR probes (213792_s_at, 226450_at, 226216_at). Values plotted in the histograms are shown as $-\log 10$ of Pearson p-values. ER: estrogen receptor status; PR: progesterone receptor status; L: pathological lymph node status; Ki67: Ki-67 protein status evaluated by immunohistochemistry; pT: pathological tumor size; NB: normal breast tissue; PB: pathological breast tissue; G: grading of gse 42568 datasets. $\mathrm{G}^{*}$ grading of gse 76124 datasets. 


\begin{tabular}{|c|c|}
\hline h-DDR1 total & $\begin{array}{l}\text { FW 5'-GCGTCTGTCTGCGGGTAGAG-3' } \\
\text { RV 5'-ACGTCAGATAAATACATTGTCT-3' }\end{array}$ \\
\hline h-IR & $\begin{array}{l}\text { FW 5'-CGTGGAGGATAATTACATCGTGTT-3' } \\
\text { RV 5'-TGGTCGGGCAAACTTTCTG-3' }\end{array}$ \\
\hline p53 & $\begin{array}{l}\text { FW 5'-CACTGCCCAACAACACCAGCTCCT-3' } \\
\text { RV 5'-GTCTGAGTCAGGCCCTTCTGTCTT-3' }\end{array}$ \\
\hline HMGA1a & $\begin{array}{l}\text { FW 5'-AGGAAAAGGACGGCACTGAGAA-3' } \\
\text { RV 5'-CCCCGAGGTCTCTTAGGTGTTGG-3' }\end{array}$ \\
\hline Sp1 & $\begin{array}{l}\text { FW 5'-TGAAAAAGGAGTTGGTGGC-3' } \\
\text { RV 5'-TGCTGGTTCTGTAAGTTGGG-3' }\end{array}$ \\
\hline $\mathrm{h} \beta$-actin & $\begin{array}{l}\text { FW 5'-GACAGGATGCAGAAGGAGATCACT-3' } \\
\text { RV 5'-TGATCCACATCTGCTGGAACC T-3' }\end{array}$ \\
\hline
\end{tabular}

Fw: forward; Rv: reverse

role in regulating ligand-dependent receptor endocytosis and sorting for degradation. However, whether DDR1 expression may affect IR ubiquitination remains to be elucidated. Further studies are required to fully clarify the molecular mechanisms associated with DDR1 action on IR trafficking and gene expression regulation.

IR overexpression and in particular IR-A isoform upregulation, as well as hyperinsulinemia and IGF-2, have a well-established role in breast cancer both in vitro and in vivo [1, 35-39]. Our data strongly suggest that DDR1 might be an important determinant of IR overexpression in breast cancer. Significantly, we have previously shown that IGF-1, IGF-2 and insulin induce DDR1 upregulation in breast cancer cells by activating the AKT/miR199a-5b pathway [24]. Others have shown that DDR1 is one of the prominent molecules expressed by sarcomas characterized by constitutive IGF-2 overexpression [40]. Thus, the IR-DDR 1 crosstalk constitutes a positive feedback loop enhancing the effects of insulin and IGF-2 in breast cancer cells.

These findings are consistent with previous data indicating that DDR1 as well as the IGF-2/IR-A loop are important regulators of prenatal growth [19] and cancer progression [20, 41].

By analyzing publicly available databases, we found that the correlation between DDR1 and IR is stronger in breast cancer specimens than in normal breast tissues. Importantly, the correlation between DDR1 and IR expression levels is even stronger in breast cancers with aggressive characteristics, such as basal-like phenotype, absence of estrogens and progesterone receptors, metastatic lymph-nodes, elevated Ki67 staining and tumor grading, confirming that this functional crosstalk might have important clinical implications in breast cancer. In this regard, our present finding that DDR1 affects both the AKT and the ERK1/2 pathways is particularly relevant, as IR/IGF-1R inhibitors proposed for cancer treatment are generally more effective in blocking the AKT pathway than inhibiting the ERK pathway, and may actually stimulate this pathway in certain models [42-44]. Thus, DDR 1 may work as a possible novel candidate in targeting the IGF-2/IR-A loop in cancer.

In summary, this study demonstrates that DDR1 associates with the IR, enhances the activation of IR downstream signaling and the mitogenic and pro-invasive effects of insulin and IGF-2 in breast cancer cells. DDR1 emerges as a novel and important regulator of IR expression by acting at multiple levels. All these effects are distinct from the previously characterized role of DDR1 as a collagen receptor. In accordance with these in vitro findings, DDR1 and IR expression levels are strongly correlated in breast cancer specimens, and especially in cancers with aggressive characteristics, suggesting that the DDR1 - IR axis could be a valuable therapeutic target in human breast cancer.

\section{MATERIALS AND METHODS}

\section{Materials}

Insulin and IGF-2 were purchased from Prepotech (Rocky Hill, NJ); bovine serum albumin (BSA), fibronectin, collagen Type IV, actinomycin D, cycloheximide, cloroquine, and MG132 from SigmaAldrich (Saint Louis Missouri, USA); Metafectene PRO from Biontex Laboratories GmbH (Germany); lipofectamine RNAiMax, Opti-MEM, fetal calf serum (FCS), Geneticin (G-418), puromycin, TRIzol Reagent, ThermoScript RT kit, SYBR Green MasterMix from Life Technologies, Inc. Laboratories (Paisley, UK); MTT, nitrocellulose membranes, HRP-conjugated secondary antibodies from Amersham Biosciences (Little Chalfont, UK). 
Constructs encoding either an empty vector (pCMV6- EV) or the human wild type DDR1 isoform a (DDR1wt) cDNAs were from OriGene (Rockville, MD, USA). The specific silencer Select Pre-designed pool of four siRNA oligos for DDR1 (Human DDR1 siGENOME SMARTpool Cat M-003111-04) and the negative control, consisting of a pool of four scramble siRNAs were from Thermo Fisher Scientific Dharmacon (NYSE:TMO). Doxycicline inducible lentivirus vectors (pTZ) encoding for DDR1 cDNA or control vector GFP were purchased from GE Healthcare Dharmacon Europe.

\section{Cell cultures}

The human cancer cell lines MCF-7, BT-474, MDAMB-157, T47D, ZR-75, MDA-MB-231, MDA-MB-468 were purchased from the American Cell Type Culture Collection and cultured according to the manufacturer's instructions. Cells were grown in Medium supplemented with $10 \%$ fetal bovine serum (FBS).

\section{Western blot analysis}

Cell lysates were subjected to Western blot analysis as previously described [45]. The following antibodies were used: anti-DDR1 (C-20), anti-IR $\beta$ (C-19), anti-p53 (DO-1), anti HMG-I/HMG-Y (FL-95) (Santa Cruz Biotechnology); anti-p-Akt (Ser473), anti-AKT, anti-pERK1/2 (T202/Y204), anti-ERK1/2, anti-Sp1 (D4C3) (Cell Signaling Technology); anti- $\beta$-actin (Sigma-Aldrich, Saint Louis Missouri, USA).

\section{Real-time PCR}

Total cellular RNA was extracted using TRIzol Reagent according to the manufacturer's protocol, as previously described [46]. qRT-PCR was used to confirm the expression levels of mRNAs. Total RNA $(2 \mu \mathrm{g})$ was reversely transcribed using the ThermoScript RT kit and oligo(dT) primers. Synthesized cDNA was combined in a qRT-PCR reaction using primers for the gene of interest (Table 1). The $\Delta \Delta \mathrm{Ct}$ method of relative quantification and SYBR Green chemistry were used to measure mRNA.

\section{Confocal microscopy}

MCF-7 cells were plated onto coverslips, serum starved for $24 \mathrm{~h}$, and then stimulated with either insulin or IGF-2. Coverslips were processed for immunofluorescence and confocal analysis at the Sidney Kimmel Cancer Center Bioimaging Core Facility, as previously described [23]. Primary antibodies used were: anti-IR (polyclonal antibody C-19, Santa Cruz Biotechnology), anti-DDR1 (polyclonal antibody C-20, Santa Cruz Biotechnology). After incubation with primary antibodies, the coverslips were incubated using secondary antibodies, goat anti- mouse IgG Alexa Fluor 488 (Invitrogen) and goat antirabbit IgG Alexa Fluor 594 (Invitrogen). Coverslips were analyzed and photographed on a Nikon AIR inverted confocal microscope with a Plan-Apo 60x oil immersion lens at room temperature and NIS Elements C software. Images were analyzed using Image J. Pictures are representative of at least 10 independent fields from three independent experiments. Fields were selected for the presence of cells with the following criteria: well defined limits, clear identification of nucleus and absence of intersection with neighboring cells. An average of 100 cells was examined for each condition. Data are representative of $\sim 80 \%$ of the total number of cells examined. Co-localization index was calculated using NIH ImageJ software.

\section{Immunoprecipitation analysis}

Cells were lysed and processed as previously described [49]. The following antibodies were used for Immunoprecipation: anti-DDR1 (monoclonal antibody MAB2396, R\&D System) and anti-HA.11 (monoclonal antibody 16B12, Covance). The following antibodies were used for Western Blotting: anti-DDR1 (policlonal antibody C-20, sc-532) and anti-IR (polyclonal antibody C-19, Santa Cruz biotechnology).

\section{Gene silencing by small interfering RNA, and gene overexpression}

For small interfering RNA (siRNA) experiments, cells were transiently transfected with a mixture containing OptiMem, Lipofectamine RNAiMax and either a pool of four scramble siRNA oligos $(10 \mathrm{nM})$ or a pool of four specific siRNA oligos for DDR1 (10nM).

For overexpression experiments, cells were transiently transfected with a mixture containing OptiMem, Metafectene PRO and the DNA of interest or the corresponding control empty vectors.

Most experiments of DDR1 overexpression were performed by transiently transfecting cells with plasmids encoding either the human constitutive pCMV6-DDR1 or the corresponding empty vector (pCMV6-EV). Cells were then processed after $48 \mathrm{~h}$, according to the aim of the experiment. As, a complementary approach to overexpress DDR1, cells were transiently transfected with a doxy-inducible pTZ-DDR1 lentiviral vector or control pTZ-GFP vector. Twenty-four hours after transfection, cells were incubated with doxycycline $(1 \mu \mathrm{g} / \mathrm{mL})$ for $48 \mathrm{~h}$ and then processed to perform the experiments of interest.

To evaluate the IR downstream signaling, transfected cells were serum starved for $24 \mathrm{~h}$, and stimulated with insulin (10nM) or IGF-2 (10nM) for $5 \mathrm{~min}$. 


\section{Cell viability}

Cell viability was measured by the methyl thiazolyl tatrazolium (MTT) test. MCF-7, MDA-MB-157 and BT-474 cell lines were plated in 48-multiwell plates under standard culture conditions. After $24 \mathrm{~h}$, cells were transfected with a pool of four DDR1 siRNA oligos or DDR1 expressing vectors and the relative negative controls. After $24 \mathrm{~h}$, cells were serum-starved for $24 \mathrm{~h}$ and then stimulated with insulin $(10 \mathrm{nM})$ or IGF-2 $(10 \mathrm{nM})$ for additional $48 \mathrm{~h}$. The cells were then incubated with medium containing $5 \mathrm{mg} / \mathrm{mL}$ MTT and processed as previously described [47].

\section{Invasion assay}

The ability of cells to invade the extracellular matrix was measured with Boyden's chamber technique as described [23]. Cells, serum starved for 24h, were placed on polycarbonate filters ( $8 \mu \mathrm{m}$ pore size, Corning Costar) coated on the upper side with $25 \mu \mathrm{g} / \mathrm{mL}$ fibronectin. Filters were placed over bottom chambers containing serum-free medium with or without ligand (10nM). After incubation for $6-8 \mathrm{~h}$, depending on the cell type, cells on the upper surface of filters were removed with a cotton swab, and the filters were stained for 30min with crystal violet $(0.05 \%$ crystal violet in PBS plus $20 \%$ ethanol). After three washes with water, crystal violet was solubilized in $10 \%$ acetic acid for $30 \mathrm{~min}$ at room temperature, and its concentration was evaluated by absorbance at $595 \mathrm{~nm}$.

\section{Cell cycle evaluation}

Cells synchronized for $24 \mathrm{~h}$ in serum-free medium were exposed to insulin (10nM) or IGF-2 (10nM) for $48 \mathrm{~h}$ and subjected to fluorescence-activated cell sorting (FACS) analysis, as previously described [48].

\section{Soft-agar colony formation assay}

Anchorage-independent growth was assessed as previously described [23] with some modifications. Briefly, a mixture of $0.66 \%$ agar and medium containing $2.5 \%$ of CS-FCS was plated on the bottom of each well plate (hard-agar). Then, cells suspended in $2.5 \%$ CS-FCS medium containing $0.33 \%$ agar (soft-agar) were plated on the top of the hard-agar layer. Top agar was then covered with culture medium with or without insulin $(10 \mathrm{nM})$ or IGF-2 (10nM). Stimulus was changed twice a week and cells were cultured for 3 weeks. Colonies were visualized with $0.5 \mathrm{mg} / \mathrm{mL}$ MTT, photographed and analyzed with NIH ImageJ.

\section{Analysis of expression correlation}

The correlation of expression between DDR1 and IR across 32 different human datasets of microarray experiments was analyzed on breast cancer biopsies and cell lines. We selected from Gene Expression Omnibus (GEO) (https://www.ncbi.nlm.nih.gov/geo) the Affymetrix GeneChip Human Genome U133A and U133 plus 2.0 arrays normalized by MAS5.0 algorithm. We computed the Pearson correlation and p-value between DDR1 and IR for each dataset considered. The Pearson value provides an index of positive expression correlation between two genes when it is positive, otherwise, negative expression correlation when it is negative. Multiple probes of DDR1 and IR transcripts were assayed in the Affymetrix chips analysis. Therefore, we separately calculated the Pearson value of three probes for DDR1 and three probes for IR. For GEO datasets showing a persistent statistically significant positive correlation between DDR1 and IR for each combination of probes, we performed a stratification analysis by separating the datasets into clinical categories and iterating the Pearson analysis. GEO ID of datasets and probes are reported in Supplementary Table 1.

\section{Densitometric and statistical analysis}

Densitometry results were obtained by using NIH ImageJ. Differences between means were evaluated by one-way ANOVA followed by post-hoc analysis of significance (Bonferroni test) for the comparison between more than two groups, whereas the Student's $t$ test for unpaired samples was used for comparisons between two groups. The level of significance was set at $\mathrm{p}<0.05$. Statistical analysis was performed with GraphPad Prism6 (GraphPad Software, San Diego, CA). Data were expressed as mean $\pm \mathrm{SEM}$.

\section{Abbreviations}

IR, insulin receptor; IR-A insulin receptor isoform A; DDR1, discoidin domain receptor 1; IIGFs, insulin/ IGF signaling; IGF-1R, insulin growth factor receptor; IGF-1, insulin growth factor 1; IGF-2, insulin growth factor 2; EMT, epithelial mesenchymal transition; PTB, phosphotyrosine binding; ERK, extracellular signalrelated kinase; 3'UTR, 3' untranslated region; HMGA1, high-mobility group protein; MTT, methyl thiazolyl tatrazolium; HRP, horseradish peroxidase; GFP, green fluorescent protein; FACS, fluorescence-activated cell sorting; FCS, fetal calf serum.

\section{Author contributions}

The authors listed below gave the following contributions. VV, RM, MLN, and AB: substantial contributions to the conception and design of the paper; VV, RM, MLN, CP, CS, MM: experimental work; MR: bioinformatic analysis; $\mathrm{VV}, \mathrm{RM}$, and $\mathrm{AB}$ drafting the work; VV, RM, MLN, CP, CS, MM, PV, MP, MR, AM, and $\mathrm{AB}$ revising it critically for important intellectual content; final approval of the version to be published; and 
agreement to be accountable for all aspects of the work in ensuring that questions related to the accuracy or integrity of any part of the work are appropriately investigated and resolved.

\section{ACKNOWLEDGMENTS}

This work was supported in part by grants from AIRC IG 19242 and PON01_01078 to AB, from Ministero della Salute, 67/GR-2010-2319511 to RM, and from National Institutes of Health Grants RO1 CA164462 to AM. The Translational Core Facility of the Sidney Kimmel Cancer Center is supported by NIH/NCI (P30CA056036).

\section{CONFLICTS OF INTEREST}

The authors declare no conflicts of interest.

\section{REFERENCES}

1. Law JH, Habibi G, Hu K, Masoudi H, Wang MY, Stratford AL, Park E, Gee JM, Finlay P, Jones HE, Nicholson RI, Carboni J, Gottardis M, et al. Phosphorylated insulin-like growth factor-i/insulin receptor is present in all breast cancer subtypes and is related to poor survival. Cancer Res. 2008; 68:10238-10246.

2. Camirand A, Zakikhani M, Young F, Pollak M. Inhibition of insulin-like growth factor-1 receptor signaling enhances growth-inhibitory and proapoptotic effects of gefitinib (Iressa) in human breast cancer cells. Breast Cancer Res. 2005; 7:R570-579.

3. O'Connor R. Regulation of IGF-I receptor signaling in tumor cells. Horm Metab Res. 2003; 35:771-777.

4. Malaguarnera R, Morcavallo A, Belfiore A. The insulin and igf-I pathway in endocrine glands carcinogenesis. J Oncol. 2012; 2012:635614.

5. Zelenko Z, Gallagher EJ, Antoniou IM, Sachdev D, Nayak A, Yee D, LeRoith D. EMT reversal in human cancer cells after IR knockdown in hyperinsulinemic mice. Endocr Relat Cancer. 2016; 23:747-758.

6. Malaguarnera R, Frasca F, Garozzo A, Giani F, Pandini G, Vella V, Vigneri R, Belfiore A. Insulin receptor isoforms and insulin-like growth factor receptor in human follicular cell precursors from papillary thyroid cancer and normal thyroid. J Clin Endocrinol Metab. 2011; 96:766-774.

7. Scotlandi K, Belfiore A. Targeting the insulin-like growth factor (IGF) system is not as simple as just targeting the type 1 IGF receptor. Am Soc Clin Oncol Educ Book. 2012:599-604.

8. King H, Aleksic T, Haluska P, Macaulay VM. Can we unlock the potential of IGF-1R inhibition in cancer therapy? Cancer Treat Rev. 2014; 40:1096-1105.
9. Baserga R. The decline and fall of the IGF-I receptor. J Cell Physiol. 2013; 228:675-679.

10. Garofalo C, Manara MC, Nicoletti G, Marino MT, Lollini PL, Astolfi A, Pandini G, Lopez-Guerrero JA, Schaefer KL, Belfiore A, Picci P, Scotlandi K. Efficacy of and resistance to anti-IGF-1R therapies in Ewing's sarcoma is dependent on insulin receptor signaling. Oncogene. 2011; 30:2730-2740

11. Frasca F, Pandini G, Scalia P, Sciacca L, Mineo R, Costantino A, Goldfine ID, Belfiore A, Vigneri R. Insulin receptor isoform A, a newly recognized, high-affinity insulin-like growth factor II receptor in fetal and cancer cells. Mol Cell Biol. 1999; 19:3278-3288.

12. Malaguarnera R, Sacco A, Voci C, Pandini G, Vigneri R, Belfiore A. Proinsulin binds with high affinity the insulin receptor isoform $\mathrm{A}$ and predominantly activates the mitogenic pathway. Endocrinology. 2012; 153:2152-2163.

13. Sciacca L, Costantino A, Pandini G, Mineo R, Frasca F, Scalia P, Sbraccia P, Goldfine ID, Vigneri R, Belfiore A. Insulin receptor activation by IGF-II in breast cancers: evidence for a new autocrine/paracrine mechanism. Oncogene. 1999; 18:2471-2479.

14. Vella V, Pandini G, Sciacca L, Mineo R, Vigneri R, Pezzino V, Belfiore A. A novel autocrine loop involving IGF-II and the insulin receptor isoform-A stimulates growth of thyroid cancer. J Clin Endocrinol Metab. 2002; $87: 245-254$

15. Morcavallo A, Gaspari M, Pandini G, Palummo A, Cuda G, Larsen MR, Vigneri R, Belfiore A. Research resource: new and diverse substrates for the insulin receptor isoform A revealed by quantitative proteomics after stimulation with IGF-II or insulin. Mol Endocrinol. 2011; 25:1456-1468.

16. Vogel WF, Abdulhussein R, Ford CE. Sensing extracellular matrix: an update on discoidin domain receptor function. Cell Signal. 2006; 18:1108-1116.

17. Leitinger B. Transmembrane collagen receptors. Annu Rev Cell Dev Biol. 2011; 27:265-290.

18. Vogel W, Gish GD, Alves F, Pawson T. The discoidin domain receptor tyrosine kinases are activated by collagen. Mol Cell. 1997; 1:13-23.

19. Leitinger B. Discoidin domain receptor functions in physiological and pathological conditions. Int Rev Cell Mol Biol. 2014; 310:39-87.

20. Borza CM, Pozzi A. Discoidin domain receptors in disease. Matrix Biol. 2014; 34:185-192.

21. Valiathan RR, Marco M, Leitinger B, Kleer CG, Fridman $R$. Discoidin domain receptor tyrosine kinases: new players in cancer progression. Cancer Metastasis Rev. 2012; $31: 295-321$. 
22. Lemeer S, Bluwstein A, Wu Z, Leberfinger J, Muller K, Kramer K, Kuster B. Phosphotyrosine mediated protein interactions of the discoidin domain receptor 1 . J Proteomics. 2012; 75:3465-3477.

23. Malaguarnera R, Nicolosi ML, Sacco A, Morcavallo A, Vella V, Voci C, Spatuzza M, Xu SQ, Iozzo RV, Vigneri R, Morrione A, Belfiore A. Novel cross talk between IGF-IR and DDR1 regulates IGF-IR trafficking, signaling and biological responses. Oncotarget. 2015; 6:16084-16105. doi: 10.18632/oncotarget.3177.

24. Mata R, Palladino C, Nicolosi ML, Lo Presti AR, Malaguarnera R, Ragusa M, Sciortino D, Morrione A, Maggiolini M, Vella V, Belfiore A. IGF-I induces upregulation of DDR1 collagen receptor in breast cancer cells by suppressing MIR-199a-5p through the PI3K/AKT pathway. Oncotarget. 2016; 7:7683-7700. doi: 10.18632/ oncotarget.6524.

25. Milazzo G, Giorgino F, Damante G, Sung C, Stampfer MR, Vigneri R, Goldfine ID, Belfiore A. Insulin receptor expression and function in human breast cancer cell lines. Cancer Res. 1992; 52:3924-3930.

26. Foti D, Iuliano R, Chiefari E, Brunetti A. A nucleoprotein complex containing Sp1, C/EBP beta, and HMGI-Y controls human insulin receptor gene transcription. Mol Cell Biol. 2003; 23:2720-2732.

27. Webster NJ, Resnik JL, Reichart DB, Strauss B, Haas M, Seely BL. Repression of the insulin receptor promoter by the tumor suppressor gene product p53: a possible mechanism for receptor overexpression in breast cancer. Cancer Res. 1996; 56:2781-2788.

28. Mihai C, Chotani M, Elton TS, Agarwal G. Mapping of DDR1 distribution and oligomerization on the cell surface by FRET microscopy. J Mol Biol. 2009; 385:432-445.

29. Vecchione A, Marchese A, Henry P, Rotin D, Morrione A. The Grb10/Nedd4 complex regulates ligand-induced ubiquitination and stability of the insulin-like growth factor I receptor. Mol Cell Biol. 2003; 23:3363-3372.

30. Monami G, Emiliozzi V, Morrione A. Grb10/Nedd4mediated multiubiquitination of the insulin-like growth factor receptor regulates receptor internalization. J Cell Physiol. 2008; 216:426-437.

31. Morcavallo A, Genua M, Palummo A, Kletvikova E, Jiracek J, Brzozowski AM, Iozzo RV, Belfiore A, Morrione A. Insulin and insulin-like growth factor II differentially regulate endocytic sorting and stability of insulin receptor isoform A. J Biol Chem. 2012; 287:11422-11436.

32. Morcavallo A, Buraschi S, Xu SQ, Belfiore A, Schaefer L, Iozzo RV, Morrione A. Decorin differentially modulates the activity of insulin receptor isoform A ligands. Matrix Biol. 2014; 35:82-90.

33. Morcavallo A, Stefanello M, Iozzo RV, Belfiore A, Morrione A. Ligand-mediated endocytosis and trafficking of the insulin-like growth factor receptor I and insulin receptor modulate receptor function. Front Endocrinol (Lausanne). 2014; 5:220.

34. Fukushima T, Yoshihara H, Furuta H, Hakuno F, Iemura SI, Natsume T, Nakatsu Y, Kamata H, Asano T, Komada M, Takahashi SI. USP15 attenuates IGF-I signaling by antagonizing Nedd4-induced IRS-2 ubiquitination. ochem Biochem Biophys Res Commun. 2017; 484:522-528.

35. Pan F, Hong LQ. Insulin promotes proliferation and migration of breast cancer cells through the extracellular regulated kinase pathway. Asian Pac J Cancer Prev. 2014; 15:6349-6352.

36. Gallagher EJ, Alikhani N, Tobin-Hess A, Blank J, Buffin NJ, Zelenko Z, Tennagels N, Werner U, LeRoith D. Insulin receptor phosphorylation by endogenous insulin or the insulin analog AspB10 promotes mammary tumor growth independent of the IGF-I receptor. Diabetes. 2013; 62:3553-3560.

37. Rostoker R, Abelson S, Bitton-Worms K, Genkin I, BenShmuel S, Dakwar M, Orr ZS, Caspi A, Tzukerman M, LeRoith D. Highly specific role of the insulin receptor in breast cancer progression. Endocr Relat Cancer. 2015; 22:145-157.

38. Rostoker R, Bitton-Worms K, Caspi A, Shen-Orr Z, LeRoith D. Investigating new therapeutic strategies targeting hyperinsulinemia's mitogenic effects in a female mouse breast cancer model. Endocrinology. 2013; 154:1701-1710.

39. Novosyadlyy R, Lann DE, Vijayakumar A, Rowzee A, Lazzarino DA, Fierz Y, Carboni JM, Gottardis MM, Pennisi PA, Molinolo AA, Kurshan N, Mejia W, Santopietro S, et al. Insulin-mediated acceleration of breast cancer development and progression in a nonobese model of type 2 diabetes. Cancer Res. 2010; 70:741-751.

40. Hajdu M, Singer S, Maki RG, Schwartz GK, Keohan ML, Antonescu CR. IGF2 over-expression in solitary fibrous tumours is independent of anatomical location and is related to loss of imprinting. J Pathol. 2010; 221:300-307.

41. Vogel WF. Collagen-receptor signaling in health and disease. Eur J Dermatol. 2001; 11:506-514.

42. Scotlandi K, Manara MC, Nicoletti G, Lollini PL, Lukas S, Benini S, Croci S, Perdichizzi S, Zambelli D, Serra M, Garcia-Echeverria C, Hofmann F, Picci P. Antitumor activity of the insulin-like growth factor-I receptor kinase inhibitor NVP-AEW541 in musculoskeletal tumors. Cancer Res. 2005; 65:3868-3876.

43. Bao XH, Takaoka M, Hao HF, Wang ZG, Fukazawa T, Yamatsuji T, Sakurama K, Sun DS, Nagasaka T, Fujiwara T, Naomoto Y. Esophageal cancer exhibits resistance to a novel IGF-1R inhibitor NVP-AEW541 with maintained RAS-MAPK activity. Anticancer Res. 2012; $32: 2827-2834$. 
44. Garofalo C, Mancarella C, Grilli A, Manara MC, Astolfi A, Marino MT, Conte A, Sigismund S, Care A, Belfiore A, Picci P, Scotlandi K. Identification of common and distinctive mechanisms of resistance to different antiIGF-IR agents in Ewing's sarcoma. Mol Endocrinol. 2012; 26:1603-1616.

45. Malaguarnera R, Sacco A, Morcavallo A, Squatrito S, Migliaccio A, Morrione A, Maggiolini M, Belfiore A. Metformin inhibits androgen-induced IGF-IR up-regulation in prostate cancer cells by disrupting membrane-initiated androgen signaling. Endocrinology. 2014; 155:1207-1221.

46. Giani F, Vella V, Nicolosi ML, Fierabracci A, Lotta S, Malaguarnera R, Belfiore A, Vigneri R, Frasca F. Thyrospheres from normal or malignant thyroid tissue have different biological, functional, and genetic features. J Clin Endocrinol Metab. 2015; 100:E1168-1178.
47. Vella V, Puppin C, Damante G, Vigneri R, Sanfilippo M, Vigneri P, Tell G, Frasca F. DeltaNp73alpha inhibits PTEN expression in thyroid cancer cells. Int J Cancer. 2009; 124:2539-2548.

48. Frasca F, Vella V, Nicolosi ML, Messina RL, Giani F, Lotta S, Vigneri P, Regalbuto C, Vigneri R. Thyroid cancer cell resistance to gefitinib depends on the constitutive oncogenic activation of the ERK pathway. J Clin Endocrinol Metab. 2013; 98:2502-2512.

49. Malaguarnera R, Vella V, Pandini G, Sanfilippo M, Pezzino V, Vigneri R, Frasca F. TAp73 alpha increases p53 tumor suppressor activity in thyroid cancer cells via the inhibition of Mdm2-mediated degradation. Mol Cancer Res. 2008; 6:64-77. 